\title{
Guidelines
}

Respiration

\section{Position Paper for the State-of-the-Art Application of Respiratory Support in Patients with COVID-19}

\author{
Michael Pfeifer ${ }^{a-c}$ Santiago Ewig ${ }^{d}$ Thomas Voshaar ${ }^{\mathrm{e}}$ \\ Winfried Johannes Randerath ${ }^{f, g}$ Torsten Bauer ${ }^{h}$ Jens Geiseler ${ }^{i}$ \\ Dominic Dellweg ${ }^{j}$ Michael Westhoff ${ }^{k}, 1$ Wolfram Windisch ${ }^{1, m}$ \\ Bernd Schönhofer $^{\mathrm{n}}$ Stefan Kluge ${ }^{\circ}$ Philipp M. Lepper ${ }^{\mathrm{p}}$
}

${ }^{a}$ Klinik und Poliklinik für Innere Medizin II, Universitätsklinik Regensburg, Regensburg, Germany; ${ }^{b}$ Abteilung für Pneumologie, Fachklinik für Lungenerkrankungen Donaustauf, Donaustauf, Germany; ${ }^{`}$ Krankenhaus Barmherzige Brüder, Klinik für Pneumologie und konservative Intensivmedizin, Regensburg, Germany; ${ }^{\text {}}$ Thoraxzentrum Ruhrgebiet, Department of Respiratory and Infectious Diseases, EVK Herne and Augusta-Krankenanstalt

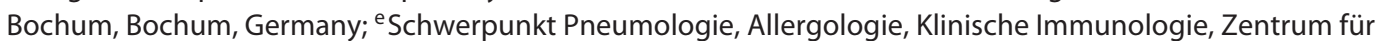
Schlaf- und Beatmungsmedizin, Krankenhaus Bethanien, Moers, Germany; ${ }^{f}$ Institut für Pneumologie an der Universität zu Köln, Cologne, Germany; ${ }^{9}$ Klinik für Pneumologie, Krankenhaus Bethanien, Solingen, Germany; h'Lungenklinik Heckeshorn, Helios Klinikum Emil von Behring GmbH, Berlin, Germany; 'Medizinische Klinik IV: Klinik für Pneumologie, Beatmungs- und Schlafmedizin, Klinikum Vest GmbH, Paracelsus-Klinik, Marl, Germany; jFachkrankenhaus Kloster Grafschaft GmbH, Akademisches Lehrkrankenhaus der Philipps-Universität Marburg, Schmallenberg, Germany; ${ }^{k}$ Klinik für Pneumologie, Lungenklinik Hemer, Hemer, Germany; 'Universität WittenHerdecke, Witten, Germany; ${ }^{m}$ Klinik für Pneumologie, Klinikum Köln-Merheim, Kliniken der Stadt Köln, Lehrstuhl für

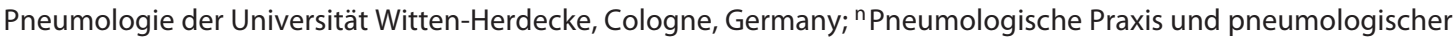
Konsildienst im Klinikum Agnes Karll Laatzen, Klinikum Region Hannover, Laatzen, Germany; ${ }^{\circ}$ Klinik für

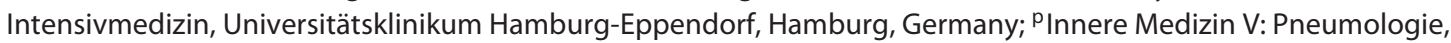
Allergologie, Beatmungs- und Umweltmedizin, Universitätsklinikum des Saarlandes, Homburg/Saar, Germany

\section{Keywords}

COVID-19 · Respiratory support · Acute respiratory failure
ID-19 can be divided into 3 phases. Pulmonary damage in advanced COVID-19 often differs from the known changes in acute respiratory distress syndrome (ARDS). Two types (type $\mathrm{L}$ and type $\mathrm{H}$ ) are differentiated, corresponding to early- and late-stage lung damage. This differentiation should be taken into consideration in the respiratory support of ARF. The assessment of the extent of ARF should be based on arterial or

This is the translation of a German article "Positionspapier zur praktischen Umsetzung der apparativen Differenzialtherapie der akuten respiratorischen Insuffizienz bei COVID-19" by Pfeifer et al. [Pneumologie. Stuttgart: Thieme; 2020]. Translated by: Dipl. Dol. G. M. Mundt. karger@karger.com www.karger.com/res

(C) 2020 S. Karger AG, Base

Karger ${ }^{\prime}=$
Prof. Dr. med. Torsten Bauer

Lungenklinik Heckeshorn, Helios Klinikum Emil von Behring GmbH Walterhöferstraße 11

DE-14165 Berlin (Germany)

torsten.bauer@helios-gesundheit.de 
capillary blood gas analysis under room air conditions, and it needs to include the calculation of oxygen supply (measured from the variables of oxygen saturation, hemoglobin level, the corrected values of Hüfner's factor, and cardiac output). Aerosols can cause transmission of infectious, virus-laden particles. Open systems or vented systems can increase the release of respirable particles. Procedures in which the invasive ventilation system must be opened and endotracheal intubation carried out are associated with an increased risk of infection. Personal protective equipment (PPE) should have top priority because fear of contagion should not be a primary reason for intubation. Based on the current knowledge, inhalation therapy, nasal high-flow therapy (NHF), continuous positive airway pressure (CPAP), or noninvasive ventilation (NIV) can be performed without an increased risk of infection to staff if PPE is provided. A significant proportion of patients with ARF present with relevant hypoxemia, which often cannot be fully corrected, even with a high inspired oxygen fraction $\left(\mathrm{FiO}_{2}\right)$ under NHF. In this situation, the oxygen therapy can be escalated to CPAP or NIV when the criteria for endotracheal intubation are not met. In ARF, NIV should be carried out in an intensive care unit or a comparable setting by experienced staff. Under CPAP/NIV, a patient can deteriorate rapidly. For this reason, continuous monitoring and readiness for intubation are to be ensured at all times. If the ARF progresses under CPAP/NIV, intubation should be implemented without delay in patients who do not have a "do not intubate" order.

(c) 2020 S. Karger AG, Basel

\section{Introduction}

Against the background of the pandemic caused by infection with the SARS-CoV-2 virus, the German Respiratory Society (DGP, Deutsche Gesellschaft für Pneumologie und Beatmungsmedizin), in cooperation with other associations, has appointed a team of experts to answer questions on how to deal with COVID-19 patients at a stage when, as far as is foreseeable at present, hospitals will not be overburdened (last updated: 04/15/2020). Due to the effectiveness of epidemiological measures such as social distancing as a result of a partial curfew, the pandemic in Germany can currently be expected to slow down and lessen in severity [1].

For this reason, great importance was attached to the accuracy of the statements even outside of a pandemic situation, and the key position statements were coordinated by the authors in an elaborate consensus process. This paper is intended as a supplement, continuation, and impetus for the development of cross-disciplinary consensus based on existing guidelines [2-5].

Previous publications on COVID-19 show a remarkable heterogeneity of accompanying symptoms of SARSCoV-2 infection. This is due to different definitions of certain disease states (e.g., shock), different but unspecified degrees of severity, different disease stages, and different populations. This renders comparisons difficult. In addition, information is currently being published quite quickly, and the patient groups described sometimes only include a few individuals.

This paper was prepared in a process compliant with the requirements of the Scientific Medical Societies in Germany (Arbeitsgemeinschaft der Wissenschaftlichen Medizinischen Fachgesellschaften, AWMF) and is subdivided into 5 thematic statements. Key points are highlighted in the form of key position statements and findings. This article is based on the current state of knowledge about COVID-19, which will improve in the short term due to the increasing number of patients in Germany. The manuscript is, therefore, already slated to be updated at the time of publication.

\section{Method}

The recommendation is based on the consensus of a group of experts against the background of a selective literature search. These experts were appointed by the Board of the DGP based on their expertise concerning the matter and their experience in structured consensusbuilding according to AWMF (Arbeitsgemeinschaft der Wissenschaftlichen Medizinischen Fachgesellschaften e.V.) criteria.

The different chapters were defined in advance and developed by teams of authors. These teams (2-3 authors in each) were given the task of preparing a draft version and developing key position statements so that the first level of consensus-building would be in a small group. Up to 3 key position statements could be made per thematic area. Authors not assigned to work on the chapters were asked to avoid commenting before consensus was reached.

The literature, on which the key position statements are based, was evaluated according to the guidelines of the Center for Evidence-Based Medicine based on the currently available data. As per the requirements of AWMFcompliant guideline development, the key position statements were worded according to a grade of recommendation (GOR), whereby grade A means "should/should not," grade B "ought to/ought not to," and grade 0 "may 


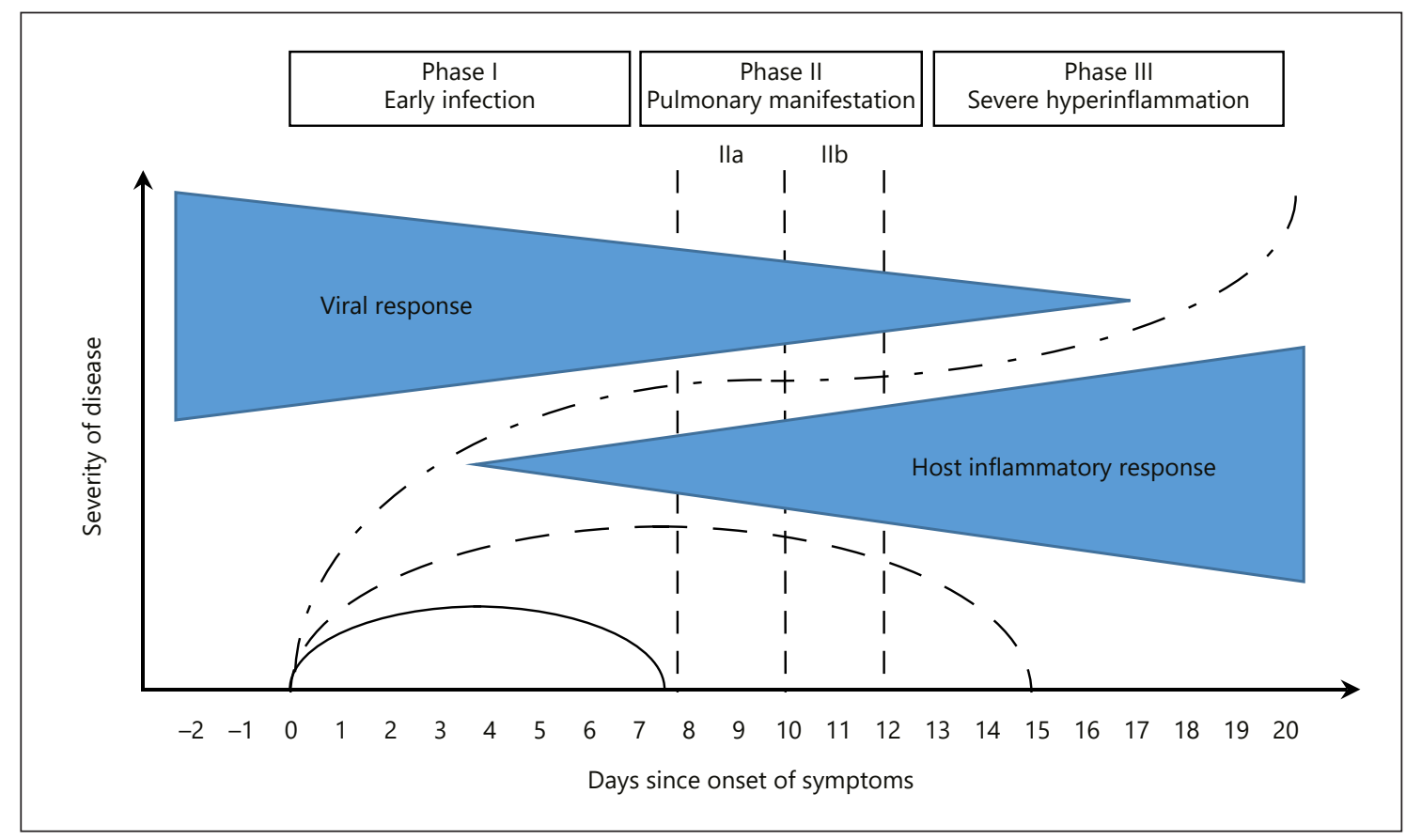

Fig. 1. Significance of immune defense and systemic inflammatory response for the symptoms of COVID-19 patients. Clinical progression of COVID-19 (mild, green; severe, grey; critical, red) over time [14, 15].

be considered/no specific recommendation." In addition, findings that were not graded but agreed upon were highlighted.

All recommendations were summarized in a joint manuscript which was edited in 4 online rounds using the Delphi technique (on the 04/13/2020, 04/14/2020, $04 / 15 / 2020$, and $04 / 16 / 2020$ ). A summary of the different recommendations and findings, as well as the expert group's approval of the manuscript, was compiled at the end of the last Delphi round.

Due to the topicality of the recommendation, a joint press release was agreed upon during 2 Delphi meetings (7/4/2020 and 8/4/2020) and communicated via the medical society. A digital press conference was held on $4 / 17 / 2020$ due to travel restrictions.

The paper will initially be published online as a position paper of DGP and the cooperating Association of Pneumological Clinics (VPK).

\section{Position Statement 1: Pathophysiology of Acute Respiratory Failure in SARS-CoV-2 Patients without Immunity}

M. Pfeifer, S. Ewig, and T. Voshaar compiled this position statement.

DGP Recommendations for Respiratory

Support in Patients with COVID-19

\subsection{General}

The COVID-19 outbreak, caused by infection with the human viral pathogen coronavirus SARS-CoV2 and first described in China in late December 2019, has become a global pandemic [6-8]. According to current studies, the disease is mild in approximately $80 \%$ of those testing positive, more severe in $20 \%$ with signs of hypoxic respiratory failure, and it requires intensive medical treatment in approx. $5 \%$ of cases [9]. The reported mortality rate is between 1 and 10\% [9] (https://coronavirus.jhu.edu/ map.html). However, these figures relate to the number of people who tested positive and underestimates the situation due to the significantly higher number of unreported cases of infected persons that can be assumed.

SARS-CoV-2 is primarily transmitted through droplets (droplet transmission); to what extent droplet nuclei (airborne transmission) or transmission by touching contaminated objects (fomite-based transmission) may play an additional role has not been conclusively established.

The virus binds to the angiotensin-converting enzyme-2 (ACE2) receptor in the lungs, a membrane-bound aminopeptidase of alveolar epithelial cells $[10,11]$. This makes the lungs the primary target organ of the virus. The virus primarily replicates in the bronchial epithelium of the upper airways, in the nasopharyngeal region, with 
further multiplication in the lower airways and the gastrointestinal mucosa $[12,13]$. At this stage, some infections are controlled by the immune response and patients can remain asymptomatic.

COVID-19 has 3 phases, which are described as follows: early infection, pulmonary involvement, and severe hyperinflammation [14, 15] (Fig. 1). During the early phase of infection, the virus infiltrates the pulmonary parenchyma and starts replicating; this triggers an inflammatory response involving local vasodilation, increased endothelial permeability, and leukocyte recruitment [16]. This focal pneumonia leads to hypoxemia and cardiovascular stress responses. Current data indicate that preexisting cardiovascular conditions and arterial hypertension are major risk factors for a lethal outcome of COVID-19 [6].

The disease is characterized by lymphopenia, which is a relevant pathognomonic sign of the infection. It is caused by apoptosis $[6,7,17]$. It is also possible that preexisting antibodies against other coronaviruses could be activated in the sense of "antibody dependent enhancement” $[18,19]$. Prolonged lymphopenia predicts poor prognosis $[6,17]$.

The marked systemic inflammation is characterized by a cytokine storm, with an increase in interleukin (IL)6 , IL-2, IL-7, tumor necrosis factor (TNF)- $\alpha$, interferon- $\gamma$, inducible protein (IP)-10, monocyte chemoattractant protein (MCP)-1, macrophage inflammatory protein (MIP)-1 $\alpha$, granulocyte-colony stimulating factor (G$\mathrm{CSF}), \mathrm{C}$-reactive protein (CRP), procalcitonin, and ferritin $[6,20-22]$.

Of prognostic relevance are the elevated or increasing concentrations of IL- 6 and ferritin $[21,22]$. In retrospective clinical studies, deceased COVID-19 patients had significantly elevated IL-6, ferritin, and CRP levels [22]. Additional prognostic markers are D-dimers and troponin $[21,22]$.

Severe, primarily local inflammation can lead to severe damage to the lung parenchyma, resulting in progressive respiratory distress. Further in the course of the disease, systemic inflammatory response can lead to multiorgan failure. In anatomical pathology studies, vasculitis and thrombosis of the small vessels can also be seen, e.g., in SARS [23]. To what extent these phenomena may play a role in an infection with SARS-CoV2 has not yet been established.

\subsection{COVID-19 and Respiratory Failure}

The severity of respiratory failure is determined by the interaction of 3 factors: (1) the severity of infection, the immune response and function, and comorbidities, (2) the patient's ventilatory response to hypoxia (hypoxic drive), and (3) the time between the onset of the initial symptoms and the start of clinical treatment.

In computed tomography (CT) images of the lungs, inflammation of the lung tissue at the onset of the disease is characterized by focal areas of ground-glass opacities seen bilaterally in regions contiguous with the pleura, mostly in the middle and lower fields [24-27]. As the disease progresses, some patients show increased density in the sense of consolidated lung areas, which, measured by radiological methods, results in an increase in lung weight [28]. It cannot be excluded that these changes are caused by additional, nosocomial pneumonia.

In terms of pathophysiology, respiratory failure is primarily characterized by mild to severe hypoxic respiratory distress. In the course of the disease, however, some patients have considerable, recurrent $\mathrm{CO}_{2}$ increases. Patients intubated and ventilated in this phase of the disease have an increased alveolar-arterial oxygen gradient (also taking into account a high inspired oxygen fraction $\left[\mathrm{FiO}_{2}\right]$ and assuming a respiratory quotient of 0.85 ) and a remarkably large difference between arterial and end-tidal $\mathrm{CO}_{2}$. In line with the changes observed in imaging and based on data in Gattinoni et al. [29], 2 chronological CT manifestations can be distinguished, the so-called type L and type H COVID-19 pneumonia (see below).

The definition of acute respiratory distress syndrome (ARDS) in accordance with the Berlin definition can be met in both manifestations; however, it has been shown that COVID-19 pneumonia, especially in the early stage (type $\mathrm{L}$ ), but also in the late stage (type $\mathrm{H}$ ), differs significantly from the familiar changes accompanying ARDS, such as those observed in septic shock or bacterial pneumonia. The following describes a model developed based on CT scans that has not been clinically or histopathologically validated at this time.

\subsection{COVID-19 Pneumonia, Type L}

This early phase, which can be compensated by the patient with oxygen support, is described as COVID-19 pneumonia, type L, by Gattinoni et al. [29], where L stands for:

- low (low elastance, i.e., high compliance)

- low ventilation/perfusion mismatch

- low lung weight with low inflammatory fluid retention, the radiological correlate of ground-glass densities, and no or little consolidation. This type, therefore, also has a low potential for recruitment. 
While, according to the Berlin definition, ARDS is present, from a functional and radiological point of view, this phase differs from ARDS in terms of diffuse alveolar damage (DAD). In DAD, the alveolar functional unit would be impaired, along with a loss of alveolar stability and the development of alveolar and interstitial edema. There are so far no systematic studies of deceased COVID-19 patients during this phase in which pathologicalanatomical findings would have correlated with imaging findings. From a pathophysiology point of view, however, the so-called type L COVID-19 pneumonia must be distinguished from ARDS. We believe this to have significant implications for the indication for respiratory support in COVID-19-related acute respiratory failure (ARF).

In the early phase of pulmonary infection, hypoxemia is the main symptom. The main difference to ARDS as we know it, in which a significant decrease in compliance due to pulmonary damage is seen, is that pulmonary elastance is preserved in COVID-19 pneumonia [29]. Data presented by Dreher et al. [30] also show a rather good average compliance in ventilated patients, underlining the difference from normal ARDS. In terms of function, this phenomenon of significant hypoxemia with maintained pulmonary compliance is most likely explained by a marked ventilation-perfusion distribution disorder. In the early phase, the viral infection leads to moderate local, subpleural inflammation with interstitial fluid accumulation (morphologically corresponding to the ground-glass pattern seen on CT). The greater part of the lungs is not affected, which explains the preserved normal pulmonary elastance [31]. In affected areas, the vessels are maximally dilated [31-33] with a postulated loss of hypoxic vasoconstriction (the Euler-Liljestrand mechanism) and there is thus an increase in shunt volume. It is not clear whether this is the result of endothelial damage or active vascular smooth muscle relaxation regulated by inflammatory mediators. The physiological response to hypoxemia is an increase in ventilation. Due to the preserved lung compliance, however, patients do not perceive this as dyspnea. This explains that no/only minor dyspnea symptoms are felt, despite pronounced hypocapnia with a $\mathrm{PaCO}_{2}<22$ $\mathrm{mm} \mathrm{Hg}$ and simultaneous significant hypoxemia.

In addition to recording the gas exchange and blood gas parameters, the leading clinical parameter is the measured respiratory rate and its changes over time, which can be interpreted as a surrogate parameter of respiratory effort. While it would be desirable and helpful to determine the respiratory effort as well as intrathoracic pressure changes by means of esophageal pressure measure- ment $[29,34]$, this approach cannot be applied in the clinical setting, especially since the technology and experience required to measure esophageal pressure are not generally available in intensive care units (ICUs). The increased respiratory rate and increased ventilation possibly lead to further lung damage due to the associated mechanical stress (shear forces and high intrapleural pressure amplitude). This phenomenon was first described experimentally by Barach et al. [35, 36] and Mascheroni et al. [37] and was labeled patient self-inflicted lung injury (P-SILI) [38]. The supply of oxygen during this phase can, to a certain extent, provide ventilatory relief. Due to an assumed shunt, however, the efficiency of oxygen delivery is potentially increasingly limited.

From a pathophysiology point of view, mechanical support by means of noninvasive ventilation (NIV) or continuous positive airway pressure (CPAP) via a mask system or helmet could be helpful during this phase to prevent possible P-SILI (see position statement 3). However, this should be viewed with caution if the support, allowing for the lowest possible mechanical load on the lungs, does not also reduce the respiratory rate to $<30 / \mathrm{min}$. In this situation, with vulnerable tissue in the lung parenchyma, a lack of synchronization between patient and ventilator or excessive pressure amplitudes will contribute to progressive damage. Whether such stress can be reduced by low-dose morphine administration needs to be clinically verified. However, the question remains, and in the event of a failure of oxygen therapy or NIV (or CPAP), on a case-by-case basis, it should be assessed whether controlled intubation and invasive ventilation should be performed to reduce the mechanical stress caused by the increased breathing effort. Finally, due to additional lung damage to be expected from invasive ventilation, extracorporeal membrane oxygenation (ECMO) should also be considered; it is certainly more lung-protective, but brings with it its own additional risks (see position statement 5 ).

\subsection{COVID-19 Pneumonia, Type $H$}

According to current studies, approximately 15-20\% of hospitalized patients develop severe lung damage. Accordingly, extensive densifications, similar to those seen in other types of severe pneumonia and patients with extrapulmonary ARDS, are seen on the CT. Such imaging patterns can also be caused by nosocomial infections.

The working group of Gattinoni et al. [29] describes the progressive, critical state as COVID-19 pneumonia, type $\mathrm{H}$ :

- high (high elastance, i.e., low compliance) as a result of increasing edema 
- high right-left shunt

- high lung weight and a high share of recruitable lung volume.

This condition reflects the pathophysiology of severe pneumogenic ARDS with signs of DAD [39]. Very similar changes were seen in patients who died of SARS [40] and MERS [41].

The model of Gattinoni et al. [29] has been shown to provide a good basis to better understand the pathophysiology of COVID-19 pneumonia. Nevertheless, many questions remain unanswered. From a clinical point of view, it is imperative to have comprehensive diagnostic procedures for both spontaneously breathing patients and particularly for postintubation patients.

In addition, assessing the patient's cardiovascular condition is of crucial importance. The first data from China showed a high proportion of cardiac patients $(20-30 \%$ of hospitalized patients) at an early stage of the pandemic. These numbers were confirmed in the European patient collectives $[6,42]$. The elevated troponin levels regularly described in studies and associated with poor prognosis must be considered an indicator of cardiac damage [21, 43]. Analysis of the deceased patients in the Wuhan cohort found cardiac damage in $34 \%$ and cardiac failure in $40 \%$, either as the sole cause or in combination with respiratory failure [21, 44-46]. In this context, the associated mortality risk of acute cardiac damage was higher than age, diabetes mellitus, chronic obstructive pulmonary disease (COPD), and preexisting cardiac disease. Several factors must be discussed as causes and, given the administration of a variety of drugs, possible drug-related toxic effects cannot be excluded; this has frequently been described. Increased cardiac stress, particularly that starting early on with the development of hypoxemia, must be assumed.

\subsection{Significance of Cardiovascular Stress}

Hypoxemia with a decrease in oxygen levels requires an increase in cardiac output to maintain adequate oxygen transport since oxygenation supply is calculated by multiplying cardiac output and oxygen saturation. At the same time, the heart can be additionally stressed as a result of hyperventilation due to an increase in right ventricular (RV) afterload. The greater respiratory effort causes an increase in the negative intrathoracic pressure, resulting in an increase in transmural left ventricular (LV) pressure. From a pathophysiology point of view, the development of hypoxemia can induce RV overload, but there is currently no evidence that this is the case in the early phase of the disease. The extent to which a severe progression goes along with increasing RV overload, as seen in severe ARDS, still requires further investigation.

As in community-acquired pneumonia (CAP), the systemic inflammatory response can foster cardiac complications such as arrhythmia, heart failure, and coronary events. However, the rate of cardiac manifestations is higher than with CAP (approx. 25\%).

Another cause of cardiac damage may be myocarditis. So far, however, only a few significant case studies are available.

To what extent the regularly identified elevated D-dimers reflect increased coagulation activity has also not yet been established. Indeed, the disease seems to be associated with an increased risk of thrombotic events and coagulation system disorders. For example, pulmonary embolism was detected in $25 \%$ of a series of 81 seriously ill COVID-19 patients [47]. It is unclear, however, whether these are thromboembolic events or in situ thromboses.

Key Statement 1.1. Two types of COVID-19 pneumonia can be distinguished, with different pathologies (type $\mathrm{L}$ and type $\mathrm{H}$ ) corresponding to early- and late-phase pneumonia.

This differentiation can be taken into consideration in the respiratory support of ARF.

Key Statement 1.2. Cardiac comorbidity, whether preexisting or COVID-19-associated, has a significant impact on both the progression and prognosis of the disease, and should therefore, always be taken into consideration during each treatment phase.

Finding 1.1: The early phase is not typical of pneumogenic ARDS. Late phases can correspond to pneumogenic ARDS; nosocomial infections and cardiac and thromboembolic complications must be considered in a differential diagnosis.

\section{Position Statement 2: Chronological Sequence and Prognosis of ARF in the Course of the Disease}

W.J. Randerath and T. Bauer compiled this position statement.

\subsection{Introduction}

The pulmonary disease COVID-19, caused by the SARS CoV-2 virus, is a pneumonia characterized by lack of immunity in the pandemic situation. Comparable diseases are infections with recombinations of the influenza virus and a lacking or low immunity in the population (e.g., influenza A/H1N1) [48]. According to the epidemiological definition, it is a type 3 pandemic with a high 
number of infected people but a comparatively low mortality. Worldwide, $6.1 \%$ of patients with confirmed infection die (https://www.who.int/docs/default-source/coronaviruse/situation-reports/20200410-sitrep-81-covid-19.pdf?sfvrsn = ca96eb84_2, accessed on 4/11/2020). However, the mortality rate is most probably significantly underestimated at present, as the estimated number of unrecorded cases is high. This assumption is also supported by the large regional differences in overall mortality, ranging from $0.9 \%$ in Korea to $7.2 \%$ in Italy $[49,50]$.

In the absence of causal treatment, COVID-19 damages the organism via 2 mechanisms, firstly, the direct cytotoxic effect of infiltration, intracellular replication, expulsion, and death of the host cell; and secondly, via the body's failure to develop sufficient immunity to control the infection. In a type 3 pandemic, it is assumed that the direct cytotoxic effect affects mortality only in exceptional cases since mortality in the early phase of the infection would have to be higher, and age and comorbidities would play a subordinate role. Zhou et al. [22] retrospectively studied 191 patients who had been hospitalized with confirmed COVID-19 disease; 54 of them died (28\%). The most frequent comorbidities were arterial hypertension (30\%), diabetes mellitus (19\%), and coronary heart disease (8\%). Multivariate analyses showed significantly increased mortality with increasing age (odds ratio [OR] 1.10, 95\% CI 1.03-1.17, per year of life; $p=00043$ ), a higher Sequential Organ Failure Assessment (SOFA) score $(5.65,2.61-12.23 ; p<0.0001)$ and D-dimers of $>1$ $\mu \mathrm{g} / \mathrm{mL}(18.42,2.64-128.55 ; p=0.0033)$. The virus was detectable up to the time of death (up to 37 days) [22].

In the chronological sequence of the disease, dyspnea occurred at a median of 13 days (range 9-16.5 days) and was not different in survivors and nonsurvivors. The 3 -stage classification system of the disease, as proposed by Siddiqi and Mehra [15], therefore seems to be clinically meaningful (Fig. 1).

\subsection{Phase I: Early Infection}

SARS-CoV-2 is introduced via ACE2, which is present in varying densities in the mucous membranes of the throat, lungs, and small intestine. Clinical symptoms include impaired taste, sore throat, cough and, more rarely, diarrhea. Swabs are taken from the nasopharynx for further testing by PCR to detect the virus. However, recent data show that nasal swabs can be negative in $27 \%$ and throat swabs in $68 \%$ of cases, even though a patient has COVID-19 [51]. The Robert Koch Institute (RKI) therefore recommends that, if COVID-19 continues to be suspected and samples from the upper respiratory tract pro- vide negative results, samples from the primary replication site of the virus, i.e., the deep respiratory tract, should also be analyzed. From a clinical point of view, the beginning of the disease is best determined by the onset of fever or flu-like symptoms [20]. All 3 clinical developments (mild, severe, and critical) can develop from phase I, depending on immunity and comorbidity.

\subsection{Phase II: Pulmonary Involvement}

Evidence of the virus in the throat is high on the first days of the disease, while pulmonary involvement only begins with viral multiplication in the lungs, marking the onset of viral pneumonia $[52,53]$. The clinical symptoms now also include shortness of breath and cough and increased density in the lungs seen on chest X-ray or chest $\mathrm{CT}$ in the form of ground-glass opacities [54]. The differentiated severity classification in this publication of phase II is phase IIa without hypoxemia $\left(\mathrm{PaO}_{2} / \mathrm{FiO}_{2} \geq 300 \mathrm{~mm}\right.$ $\mathrm{Hg}$, corresponding to an arterial or capillary $\mathrm{PaO}_{2}$ of $\geq 63$ $\mathrm{mm} \mathrm{Hg}$ on room air) and phase IIb with hypoxemia $\left(\mathrm{PaO}_{2} / \mathrm{FiO}_{2}<300 \mathrm{~mm} \mathrm{Hg}\right.$, corresponding to an arterial or capillary $\mathrm{PaO}_{2}$ of $<63 \mathrm{~mm} \mathrm{Hg}$ on room air) seems to be plausible with regard to the initial decision concerning the respiratory support and place of care for COVID-19 patients [15]. The initial assessment of hypoxemia under supplemental oxygen using conversion tables is unreliable and has not been validated in nonventilated patients.

Concerning the practical implementation of respiratory support in ARF, see recommendation 3 of this manuscript for phase IIa and recommendations 4 and 5 for phase IIb and subsequent stages.

COVID-19 patients in phase II are mainly treated in hospitals, and medication can currently not influence the progression of the disease with sufficient certainty. Hence, the adequate treatment of comorbidities and the monitoring of organ function are of crucial importance. Figure 1 provides an example of clinical progression. The following parameters should be measured at regular intervals in phase II to be able to detect the indicators of critical processes as early as possible (therapy monitoring).

\subsection{Therapy Monitoring}

The SOFA score is a significant predictor of mortality in multivariable analysis (older age, higher SOFA score, and $\mathrm{D}$-dimer $>1 \mu \mathrm{g} / \mathrm{mL}$ on admission) [22]. In univariate comparison, the SOFA score (nonsurvivors 4.5 [range 4-6] vs. survivors 1.0 [range 1-2]) and quick (q)SOFA score (nonsurvivors 1.0 [range 1-1] vs. survivors 0 [range $0-2]$ ) provided a similarly effective differentiation. The SOFA score includes the assessment of the lungs $\left(\mathrm{PaO}_{2} /\right.$ 
$\mathrm{FiO}_{2}$ ), the nervous system (the Glasgow Coma Scale, GCS), the cardiovascular system (catecholamine dosage), liver function (bilirubin), coagulation (thrombocytes), and kidney function (creatinine). COVID-19 outside the ICU is usually not associated with septic conditions, which means that monitoring of respiratory rate, clouding of consciousness, blood pressure, and $\mathrm{SaO}_{2}$ should suffice (qSOFA) [55].

A differential blood count is recommended at admission and throughout treatment because of the presumed predictive power of lymphocyte concentration. In the analysis by Zhou et al. [22], a lymphocyte count of $<800 /$ $\mu \mathrm{L}$ was more prevalent in nonsurvivors (76 vs. $26 \%, p<$ 0.0001 ). Persistently low lymphocyte concentrations are described more frequently in nonsurvivors in the publication by Wang et al. [20].

Myocardial damage ("cardiac injury") defined as elevated troponin levels (high-sensitivity troponin I [hs$\mathrm{TnI}]>28 \mathrm{ng} / \mathrm{L}$, corresponding to the upper limit of the 99\% percentile of the analysis system used) was observed less frequently in survivors than in nonsurvivors (15 vs. $28 \%$ ) [6]. In a multivariate analysis of 416 patients, myocardial damage, and the development of ARDS were independent risk factors for nonsurvival (Kaplan-Meier, log-rank test) [56, 57].

\section{D-Dimers}

Coagulation disorders are an important factor in assessing the severity of the disease in patients with severe infections in the context of sepsis [58]. In 3 retrospective studies, elevated D-dimers, especially if they remained elevated during the course of the disease, were associated with a higher probability of death $[20,22,59]$. Yin et al. [60] compared the partial thromboplastin time (PTT), platelet count, and D-dimers in COVID-19 patients with those in patients with severe pneumonia from other causes. They found no difference in D-dimer levels (COVID-19: $1.94 \mu \mathrm{g} / \mathrm{mL}$ [range 0.90-9.44] vs. non-COVID-19 $2.25 \mu \mathrm{g} / \mathrm{mL}$ [range 1.40-5.81]). However, the absolute D-dimer values in both groups were, in all cases, above the upper limit of $0.5 \mu \mathrm{g} / \mathrm{mL}$. Although the platelet count was slightly elevated in COVID-19 patients, it was still consistently within the reference range. Whether the observed coagulation disorders in COVID-19 patients are specific to SARS-CoV-2 infection or should be interpreted in the context of (incipient) sepsis cannot be answered at present.

The following additional laboratory parameters may also indicate severe disease progression: elevated liver enzymes, lactate dehydrogenase (LDH), and creatinine. El- evated inflammatory parameters such as CRP, IL-6, and ferritin are also indicators of an unfavorable prognosis [20].

\subsection{Phase III: Hyperinflammation}

An insufficient humoral immune response, and thus insufficient inactivation and elimination of SARS-CoV-2 leads to the hyperinflammatory phase III, with an increased incidence of organ failure and, specifically, the possibility of additional lung damage in the form of ARDS. The development of ARDS is largely independent of the damaging pathogen and can occur in pneumonia as well as in extrapulmonary single- or multiorgan damage. From a pathophysiology point of view, hyperinflammation in COVID-19 due to the lack of an immune response is crucial [61]. Based on the current Berlin definition of ARDS, the onset of the disorder can be within 1 week of the occurrence of risk factors or new or increasing respiratory symptoms and is therefore relevant for the characterization of COVID-19 pneumonia [62]. Under nosological aspects, however, the ARDS definition is not fully transferable to COVID-19 (see position statement 1). It also includes 3 degrees of severity which have not been differentiated in all publications:

- mild: $\mathrm{PaO}_{2} / \mathrm{FiO}_{2}=201-300 \mathrm{~mm} \mathrm{Hg}$ with positive endexpiratory pressure (PEEP) or CPAP $\geq 5 \mathrm{cmH}_{2} \mathrm{O}$

- moderate: $\mathrm{PaO}_{2} / \mathrm{FiO}_{2}=101-200 \mathrm{~mm} \mathrm{Hg}$ with PEEP $\geq 5 \mathrm{cmH}_{2} \mathrm{O}$

- severe: $\mathrm{PaO}_{2} / \mathrm{FiO}_{2}<100 \mathrm{~mm} \mathrm{Hg}$ with PEEP $\geq 5 \mathrm{~cm}$ $\mathrm{H}_{2} \mathrm{O}$.

In the context of COVID-19 pneumonia, the Berlin definition was not consistently applied in the publications described below, which means that a comparison of the clinical outcomes is subject to reservation. Nevertheless, we would like to present these results for orientation purposes.

The temporal analysis of the data of COVID-19 patients in intensive care shows that the median onset of dyspnea in this group of patients was 6.5 days after the onset of the first symptoms. However, moderate to severe ARDS then developed rapidly, within a median of 2.5 days after the onset of dyspnea [22, 63, 64]. Wang et al. [20] described the characteristics and development of 138 hospitalized COVID-19 patients. A total of $26 \%$ had to be transferred to ICUs due to complications, $61 \%$ of which were due to ARDS. The median $\mathrm{PaO}_{2} / \mathrm{FiO}_{2}$ was $136 \mathrm{~mm}$ $\mathrm{Hg}$ (range 103-234 $\mathrm{mm} \mathrm{Hg}$ ), which means that most patients had moderate to severe ARDS. Other reasons were arrhythmia (44\%) and shock (31\%). The average time from admission to moderate to severe ARDS in this col- 
lective was 8 days. Patients requiring intensive care received the following respiratory support for ARF: nasal high-flow therapy (NHF; 11\%), NIV (42\%), and invasive ventilation $(47 \%)$ [20].

The study by Wu et al. [65], which does not contain a definition of ARDS or its severity, must be viewed critically in this context. The composition of respiratory support therapies in the ARDS cohort $(n=84)$ in this study (NHF 20\%, NIV 73\%, and invasive ventilation \pm ECMO $7 \%$ ) suggests that these were predominantly mild cases.

A different group was studied by Yang et al. [64], consisting of 52 critically ill adults in a cohort of 710 patients with SARS-CoV-2 pneumonia. After 28 days, 32 patients had died, on average 7 days after being transferred to ICU. In critically ill patients, pronounced hypoxemic respiratory failure and ARDS were the predominant features, while hypercapnic failure occurred only in rare cases. Mechanical ventilation (MV) was required in $42-$ $100 \%[6,20,64]$.

The risk factors for developing ARDS described to date include age, concomitant diseases, a high fever $>39^{\circ} \mathrm{C}$, a history of smoking, and laboratory parameters (marked lymphopenia and elevated procalcitonin levels) $[63,66]$.

According to initial reports, the intensive care period is described as extended and weaning as delayed. Reported recovery times are up to 6 weeks. Typical complications in connection with COVID-19-associated ARDS include acute renal failure (29\%), elevated liver parameters $(29 \%)$, and cardiac damage (23-33\%) such as cardiomyopathy, pericarditis, cardiac arrhythmia, and sudden cardiac death. However, these usually only occur when the pulmonary symptoms have already subsided $[63,64]$. Multiorgan failure, septic shock (13\%), and secondary pneumonia are described less frequently (12\%).

Key Statement 2.1. The assessment of the extent of ARF in COVID-19 pneumonia should be based on arterial or capillary blood gas analysis on room air. It must include the calculation of oxygen supply (measured from the parameters of oxygen saturation, hemoglobin, corrected values of Hüfner's factor and cardiac output).

Key Statement 2.2. The clinical assessment of the progression of COVID-19 pneumonia patients should include clinical monitoring (e.g., qSOFA) as well as laboratory parameter-based monitoring (at least D-dimers, CRP, PCT, platelets, LDH, troponin, ferritin, and NTproBNP) to detect multiple organ failure, in conjunction with another parameter of respiratory failure (e.g., $\mathrm{SaO}_{2}$ ).

Finding 2.1. COVID-19 progresses in 3 sequential disease phases (early infection, pulmonary disease, and hyperinflammation).

DGP Recommendations for Respiratory

Support in Patients with COVID-19

\section{Position Statement 3: Oxygen Insufflation, NHF, NIV, and Invasive Ventilation with Special Consideration of Infectious Aerosol Formation}

J. Geiseler and D. Dellweg compiled this position statement.

\subsection{Principles of Aerosol Physics and Transmission of}

Infectious Particles

Sars-CoV-2 has a diameter of between 60 and $140 \mathrm{~nm}$ [67]. The main transmission route of the virus is aerogenic spread. Viruses can be detected on surfaces by PCR but cannot be cultured there. The viruses are transported through aerosols produced in the respiratory tract of infected individuals [68]. Another important aspect is that the infectivity of viruses already decreases in the aerosol. When the quantity of viral RNA and the quantity of vital, and thus potentially infectious, virus in influenza A were examined simultaneously in an experiment, the number of vital and thus infectious viruses was reduced by a factor of $10^{2}$ after only $90 \mathrm{~min}$ - despite there being same quantity of viral RNA [69].

\subsection{Physical Properties of Aerosols}

The following aspects are important for the spread of aerosols from human lungs: aerosol formation, release, and behavior in a room as well as aerosol deposition after reinhalation by another person.

\subsubsection{Formation and Release}

The release of aerosols requires energy, whereby the energy of normal resting breathing is already sufficient $[68,70-72]$. Coughing or sneezing increases the exit speed by a factor of approximately 4 vs. resting breathing [73]. The maximum range of the aerosol cloud in front of a person's face does not differ significantly and is $0.6 \mathrm{~m}$ for normal breathing, $0.6 \mathrm{~m}$ for sneezing, and $0.8 \mathrm{~m}$ for coughing [73]. However, looking at particle quantity or mass is not sufficient to evaluate the infectiousness. The virus concentration in the particles also matters. It can differ by a factor of 32 in patients with acute viral infection [74].

\subsubsection{Behavior of Aerosols in a Room}

Aerosols are solid or liquid particles suspended in gases (in this case, air) with a diameter of approximately $0.001-100 \mu \mathrm{m}$. The aerodynamic diameter $\left(\mathrm{d}_{\mathrm{ae}}\right)$ is an important parameter for the essential dispersion mechanisms of sedimentation and impaction. It is calculated as the ratio of particle size $\left(\mathrm{d}_{\mathrm{o}}\right)$ and particle density $(\mathrm{p})$ $\left(\mathrm{d}_{\mathrm{ae}}=\mathrm{d}_{\mathrm{o}} / \mathrm{p}\right)$. The mass median aerodynamic diameter 
Table 1. The sedimentation/diffusion ratio as a function of particle diameter [75]

\begin{tabular}{lll}
\hline Particle diameter, $\mu \mathrm{m}$ & Sedimentation, $\mu \mathrm{m} / \mathrm{s}$ & Diffusion, $\mu \mathrm{m} / \mathrm{s}$ \\
\hline 0.01 & 0.07 & 340 \\
0.1 & 0.7 & 38 \\
1 & 38 & 8 \\
5 & 740 & 3 \\
10 & 2,910 & 2 \\
100 & 72,000 & 1 \\
\hline
\end{tabular}

(MMAD) is generally used to classify aerosols. However, the ability of an aerosol particle to transport viruses depends on the particle mass. It is important to note that the mass depends upon the third power of the diameter. A particle with a diameter of $10 \mu \mathrm{m}$ has the same mass as 1,000 particles of $1 \mu \mathrm{m}$ [75].

Exhaled aerosols change their particle size depending on the relative humidity of the environment. The particles shrink at low humidity but can increase in size at high humidity and thus change their physical properties [76].

In an unconfined space, the force of gravity causes particles to sediment. According to Stoke's law, the frictional force of the air prevents sedimentation below a particle size of $0.5-1 \mu \mathrm{m}$. Aerosols of this size thus remain at almost a constant level in a room and can be inhaled. As larger-mass aerosols sink faster, the risk of encountering these will be greatest near the aerosol source (i.e., the patient) (Table 1). In general, the question arises as to whether smaller aerosol particles that do not immediately sink are also present in the air of patient rooms in concentrations able to cause infections. Since these data are not available for coronaviruses, the following statements are mainly based on experiments and measurements with influenza viruses. Blachere et al. [77] were able to measure room air samples and found that $46 \%$ of the virus particles were seen in aerosol particles $>4 \mu \mathrm{m}$. However, $49 \%$ of viruses were found in particles with a size of 1-4 $\mu \mathrm{m}$ and $4 \%$ in particles $<1 \mu \mathrm{m}$. Fabian et al. [72] even found $99 \%$ of viral DNA in particles $<5 \mu \mathrm{m}$. Both studies therefore found that $99 \%$ of viruses were in the respiratory aerosol fraction and were able to remain airborne for several hours. In samples taken from room air in health care facilities as well as day-care centers and aircraft cabins during the influenza season, $5.8 \times 10^{3}$ to $3.7 \times 10^{4}$ copies of the virus were found per cubic meter of room air [78], which is 2- to 20-times the number of viral particles needed to establish an infection [79]. This would mean that, assuming a ventilation of $10 \mathrm{~L} / \mathrm{min}$, this threshold would already be reached after $5 \mathrm{~min}$ in a worst-case scenario, and after $50 \mathrm{~min}$ in a best-case scenario. Also to be included in the consideration is the vitality (survival time) of the virus in aerosols. New experimental data on coronavirus have shown that Sars-CoV-2 in aerosols has a half-life of $1.1 \mathrm{~h}$ [80]. Whether a critical steady-state virus concentration in a patient room is possible also depends on the patient's viral load (low- or super-spreader), the respiratory minute volume, and the size and ventilation of the room. In general, aerosol transmission of viruses seems to be quite possible. Calculation models assume, for example, that approximately $50 \%$ of all influenza cases are transmitted in this way [81].

The square of the particle diameter, the particle density, and the viscosity of the gas (in this case, room air) also influence sedimentation velocity. In addition, particles $<1 \mu \mathrm{m}$ are subject to Brownian motion and diffuse.

The particles thus remain in the air for different lengths of time before they deposit. Although an increased risk of infection has not yet been proven, systematic room ventilation should be ensured, and the wearing of masks in accordance with current RKI recommendations is advised. Some authors suggest that the arbitrary classification in aerosols and nonaerosols based on size facilitates practical handling [82], but this does not adequately reflect aerosol physics as such.

\subsubsection{Aerosol Deposition following Inhalation}

Aerosol particles up to a size of approx. 3-4 $\mu \mathrm{m}$ follow their carrier gas. In addition, mass inertia causes particles to try and move straight ahead when the direction of airflow changes. When a surface is hit, this is called impaction. The glottis region in the upper respiratory tract is where the inspiratory flow undergoes the greatest change of direction. Smaller particles, therefore, have a higher probability of being inhaled into the lower respiratory tract and reaching the alveolar epithelial cells, although particles with an MMAD of approximately $10 \mu \mathrm{m}$ still have a $50 \%$ probability of being deposited at least within the bronchi [83].

\subsection{Aerosols in Respiratory Support Therapy}

Additional external pressure or flow is applied to the respiratory system by NHF, CPAP, NIV, or invasive ventilation. A study on invasive ventilation was able to show that the number of exhaled particles increases along with a higher expiratory (E)PAP (in this case $>5 \mathrm{~cm} \mathrm{H}_{2} \mathrm{O}$ ) [84]. Since respirable aerosols are produced at alveolar level, it appears that increased alveolar recruitment can thus result in increased aerosol formation. 


\subsubsection{Noninvasive Ventilation}

Simonds et al. [82] were able to demonstrate that, in patients with cold symptoms who were ventilated with vented NIV, the number of particles $>3 \mu \mathrm{m}$ increased significantly at $1 \mathrm{~m}$ from the patient's head. At close range (20 cm from the patient's head), on the other hand, only the number of particles $>10 \mu \mathrm{m}$ increased, although this refers to patients with symptoms of a common cold or increased secretion. No increased spread of particles of any size was found in healthy subjects. In contrast, when a nonvented mask with a filter was used, the number of particles emitted decreased at $20 \mathrm{~cm}$ and at $1 \mathrm{~m}$ in all subjects, although not significantly. A simulation model using smoke particles as a proxy for droplets showed that the airflow from the vented system covered a maximum distance of 0.6 [85] and $0.85 \mathrm{~m}$, respectively [86]. For mask leakages, the reach of leakage flow was $<10 \mathrm{~cm}$ [87]. We found no data on aerosol formation in NIV using dual-hose systems during our literature search. Since these systems work with nonvented masks, and infectious aerosols can be removed from expired air by installing a virus filter, the risk of generating potentially infectious aerosols is assumed to be as low as when using single-hose systems with nonvented masks. In a retrospective analysis of 9 SARS patients, Fowler et al. [88] calculated the relative risk (RR) of infection transmission to be 2.33 (95\% CI $0.25-21.76 ; p=0.5$ ) for healthcare workers attending to patients on NIV. However, the risk in these cases was not significantly increased, and the study did not provide any information about the mask systems used. A retrospective analysis of virus transmissions to hospital staff during the SARS epidemic in 2003 showed an increased risk of infection to the staff involved in the application of NIV [89]. However, that study also showed that simply recording a patient's ECG was associated with an even greater risk of infection, regardless of ventilation status.

\subsubsection{Invasive Ventilation}

Invasive ventilation first requires intubation. During the SARS epidemic in Canada, Fowler et al. [88] described a RR of infection of 13.3 for the intubation procedure. Thompson et al. [90] studied the viral RNA content of aerosols during various procedures in the context of the H1N1 epidemic in England. They found a significantly higher exposure to viral RNA from particles sized $<7.3$ $\mu \mathrm{m}$ while patients were being intubated. The reach of aerosol contamination in a simulation model was up to $2 \mathrm{~m}$ around the patient's head [91]. Wearing appropriate protective equipment is therefore absolutely essential. In addition, this last paper proposed placing a box over the patient's head to prevent aerosol contamination, although this has the downside that hand mobility during manipulation is restricted. The OR of aerosol production during intubation is 2.3. Endotracheal aspiration of a ventilated patient in the same study yielded an OR of 4.11 with respect to the production of virus-laden aerosols. No data on viral transmission in invasively ventilated patients outside of procedures have been published to date. If, for example, a defective or insufficiently blocked cuff can lead to aerosol formation is not known. Furthermore, not all ventilators have a virus filter in their expiratory limb. No data on this are available in published literature.

\subsubsection{Nasal High-Flow Therapy}

Transnasal flows of up to $80 \mathrm{~L} / \mathrm{min}$ are generated during NHF. The air clears dead space and generates a positive airway pressure. Bräunlich et al. [92] were able to demonstrate that the clearance and pressure effect can also be detected in the small airways. The increased transnasal inflow of air leads to an equally increased outflow of air from the nose and mouth. Exhaled air dispersion, marked with smoke particles for visualization, increased from 6.5 to $17.2 \mathrm{~cm}$ with an increase in nasal flow from 10 to $60 \mathrm{~L} / \mathrm{min}$ [93]. In a study by Kotoda et al. [94], no infectious particles were dispersed via NHF from the yeast particle-laden airways of a medical training manikin. Leung et al. [95] investigated bacterial excretion at 0.4 and $1.5 \mathrm{~m}$ from the patient's head in patients with bacterial pneumonia. They compared the use of NHF versus a simple oxygen mask in a room with 6-12 air exchanges per hour. They found no quantitative difference in terms of pathogen dispersal between the 2 types of treatment, although it can be assumed that an oxygen mask significantly reduces the expiratory flow. A recent study from China recommends the wearing of surgical masks for patients being treated with NHF, but does not provide any data on the achieved degree of infection protection or the possible limitations to the effectiveness of NHF [96].

\subsubsection{Nebulizer Systems}

Simonds et al. [82] described a sharp increase in aerosol volume near patients after inhalation with a jet nebulizer. However, their otherwise well-conducted study contains a systematic flaw in this respect, as aerosols from the nebulizer that did not even reach the patient were included in the measurement. Two retrospective analyses of the procedural risk of nebulizer applications were conducted during the 2003 SARS epidemic in Canada [89, 97]. Neither study could confirm an increased risk of infection for the medical staff performing the nebulizer 
treatment. However, it should be emphasized that simple isotonic saline inhalation reduces the release of bioaerosols from the lungs by an average of $72 \%$ for up to $6 \mathrm{~h}$ [98]. The reason for this seems to be the modified surface tension of the liquid film coating the respiratory epithelia.

\subsubsection{Oxygen Therapy}

In the study conducted by Simonds et al. [82], oxygen administration via a Venturi mask did not result in increased aerosol formation near the patient. If the exhaled air of an artificially breathing manikin is marked with smoke particles for visualization, the exhaled air can be visualized up to $0.2,0.22,0.3$, and $0.4 \mathrm{~m}$ from the manikin's face when oxygen is administered at $4,6,8$, and 10 $\mathrm{L} / \mathrm{min}$ through a Venturi mask [86]. In the same experiment, the application of 1 or $5 \mathrm{~L}$ of $\mathrm{O}_{2}$ via oxygen therapy glasses produced an expiratory "cloud" of $0.66 \mathrm{~m}$ or $1 \mathrm{~m}$.

Manipulation in connection with oxygen therapy was shown to be a risk factor for viral transmission to medical staff in one study [97], but in another it was not [89].

\subsubsection{Summary}

Aerosol physics shows that transmission of infectious, virus-containing particles via aerosols is a theoretical possibility. In particular, medical staff are concerned about an increase in activity at the patient's bedside, especially in connection with NIV, and thus possible exposure to potentially infectious aerosols.

The evidence regarding the use of oxygen therapy, NHF, CPAP, and NIV is limited in terms of comparability due to the different approaches taken to demonstrate aerosols, but also due to different room conditions (with/ without a regular air exchange). For the assessment of the treatment situation, it appears essential to use the aerosol production of spontaneously breathing and also of coughing patients for comparison purposes. Here, a minor increase in aerosol range is observed as a result of the technical manipulations. However, it is less than with invasive ventilation, which is sometimes recommended as "protective intubation" to protect medical staff against infectious aerosols. Based on a comparison with data on intubation and endotracheal aspiration, the authors found that the latter goes along with a significantly higher risk of aerosol exposure.

Key Statement 3.1. Open systems or vented systems (so-called vented masks) can increase the release of respirable particles. Mask leakage plays a rather subordinate role in aerosol formation. Closed systems (so-called nonvented masks) with an upstream virus deactivation filter in the expiratory system are safe and do not lead to in- creased aerosol formation. By analogy, dual-hose systems with virus deactivation filters in the expiratory tube are also safe and do not lead to increased aerosol formation.

Key Statement 3.2. Closed suction systems should be used for suctioning via tube or tracheal cannula. During invasive ventilation, it is important to ensure that exhaled air is filtered accordingly. In the absence of appropriate filters in the ventilator, virus deactivation filters should be used in the expiratory limb.

Key Statement 3.3. Based on current knowledge, inhalation therapy, NHF, CPAP, or NIV can be carried out by staff wearing PPE (goggles, an FFP2 or FFP3 mask, and a gown) without an increased risk of infection.

Finding 3.1. Endotracheal intubation carries a high risk of infection. Procedures in which the invasive ventilation system needs to be opened are associated with an increased risk of infection.

Finding 3.2. NHF extends the exhaled aerosol reach by several centimeters. To date, a relevant increased release of infectious aerosols compared to spontaneously breathing patients could not be demonstrated in an in vitro or an in vivo setting.

Finding 3.3. Although nebulizers with nozzles increase the amount of aerosol in room air, they do not increase the risk of infection for medical staff. The inhalation of isotonic saline solution significantly reduces aerosol release from the lungs.

Finding 3.4. Oxygen administration via mask or nasal tube does not lead to increased aerosol formation. Different oxygen systems (nasal tubes, oxygen masks, and Venturi masks) can deflect the air during exhalation in various ways. Only nasal tubes with high oxygen flows have a longer range than those used under spontaneous breathing.

\section{Key Position Statement 4: NIV in Acute Respiratory Failure}

M. Westhoff, W. Windisch, and B. Schönhofer compiled this position statement.

\subsection{Introduction}

In the context of the COVID-19 pandemic, approximately $5-6 \%$ of patients had severe hypoxemia requiring intensive care treatment, many requiring invasive ventilation or NIV $[9,64]$. Hypoxemic respiratory failure is caused either by severe pneumonia or a subsequently developing ARDS-like condition. Severe pneumonia is defined by the presence of fever or a suspected respiratory infection, and a respiratory rate of $>30 / \mathrm{min}$, severe short- 
ness of breath, or $\mathrm{SpO}_{2}<90 \%$ on room air. The diagnosis of ARDS is based on the guidelines or recommendations available to date, with appropriate classification into mild, moderate, and severe ARDS based on $\mathrm{PaO}_{2} / \mathrm{FiO}_{2}$ ratios $[5,62,99-104]$. The following section explains the options and limitations of NIV in ARF. Any therapy escalation requires the definition of a therapy goal based on the patient's will, which should be discussed at the initial doctor-patient contact and then verified daily $[3,105]$.

\subsection{Pathophysiology}

Severe respiratory failure in ARDS is believed to be caused by an intrapulmonary ventilation/perfusion mismatch or shunt [106]. Recent data on ARDS in COVID-19 shows that the underlying pathophysiological changes can be manifold. For example, Gattinoni et al. $[29,34]$, in their studies on invasively ventilated patients who met the Berlin definition of ARDS, found that, in contrast to typical ARDS, so-called "atypical ARDS" may be seen. This was characterized by a loss of lung perfusion regulation and hypoxic pulmonary vasoconstriction with maintained mechanical function of the lungs. Furthermore, it was found in some patients, that improved oxygenation under PEEP was not always the result of improved lung tissue recruitability $[29,34,107]$. This resulted in different settings of the ventilation pressures, especially PEEP, and the effectiveness of the prone position $[29,34,107]$. However, since the statements made by the authors refer solely to invasively ventilated patients who had already been on NIV and invasive ventilation for different lengths of time, their transferability to NIV therapy for ARF in COVID-19 is currently limited.

\subsection{Indication Algorithm}

The initial therapy of hypoxemia and respiratory failure focuses on oxygen administration via nasal tube, Venturi mask, and NHF. Once the gas exchange deteriorates progressively and oxygen demand increases, an indication for CPAP or ventilation should be reviewed. In addition to the indication, both the appropriate timing and type of ventilation, be it invasive or noninvasive, needs to be determined. In the case of a "do not intubate" (DNI) order, it should be established whether at least NIV, as described in the current [German] S3 guideline of NIV for ARF, is desired [5].

If an indication for ventilation applies, the focus in traditional ARDS is on increasing the transpulmonary pressure and improving or normalizing the residual capacity to improve the gas exchange disorder. A high and constantly applied PEEP can prevent alveolar collapse and be

DGP Recommendations for Respiratory

Support in Patients with COVID-19 used to achieve recruitment of collapsed alveolar regions. Due to mask leakage or intolerance, which makes longterm maintenance of PEEP possible only to a limited extent, and, in consequence, causes rapidly recurring derecruitment and consecutive gas exchange deterioration, the usefulness of NIV is limited as the severity of ARDS increases [5, 99].

Using NIV in moderate and severe ARDS leads to therapy failure in $>50 \%$ of cases. This is associated with mortality rates of almost $50 \%$ in severe ARDS $[5,99]$. Besides the severity of the current clinical condition (a Simplified Acute Physiology Score [SAPS] >37), the extent of the oxygenation disorder is a predictor of NIV failure; a $\mathrm{PaO}_{2} / \mathrm{FiO}_{2}$ ratio $<150 \mathrm{~mm} \mathrm{Hg}$ is described as the critical limit for increased mortality [108].

High tidal volumes $(>9.2$ or $9.5 \mathrm{~mL} / \mathrm{kg})$ under NIV are associated with increased mortality [108-111]. This leads to the conclusion that NIV only has a positive impact on the outcome if it can be used to provide lung-protective ventilation with a correspondingly high PEEP in normal ARDS [109]. Spontaneously breathing patients with hypoxemic ARF exhibit high respiratory drive with high breathing volumes, and thus a potentially damaging transpulmonary pressure variation $[34,38]$. Since the patient's respiratory drive is maintained under NIV, additional and (in particular) excessively high inspiratory pressure support in the context of NIV can require an increased and thus potentially risky high respiratory volume, worsening the damage to the lungs. In such situations, NIV no longer protects the lungs, as the tidal volumes considered to be lung protective cannot be applied [112]. This connection is also underlined by Gattinoni et al. [34] in their study of atypical ARDS in COVID-19. With reference to the study of Brochard et al. [38], they recommend intubation to avoid excessive intrathoracic negative pressures and P-SILI in patients with clinical signs of excessive inspiratory effort under CPAP or NIV.

A therapy attempt with noninvasive procedures in the form of NIV or, primarily, CPAP with escalation to NIV, can be made in cases of hypoxemic respiratory insufficiency and insufficient response to pure oxygen administration or in mild ARDS, especially in cases of predominantly hypercapnic respiratory insufficiency (e.g., cardiac comorbidity, COPD, obesity hypoventilation, and neuromuscular disease) $[5,99]$. The current recommendations in Italy, for example, primarily call for high CPAP pressures, escalating the NIV only later [113]. On the other hand, only $11 \%$ of the ICU patients in Lombardy were treated with NIV [49]. Patients were intubated at a median $\mathrm{PaO}_{2} / \mathrm{FiO}_{2}$ of $160 \mathrm{~mm} \mathrm{Hg}$, with subsequent high PEEP requirements. 
Fig. 2. Respiratory support options in COVID-19-related acute respiratory failure.

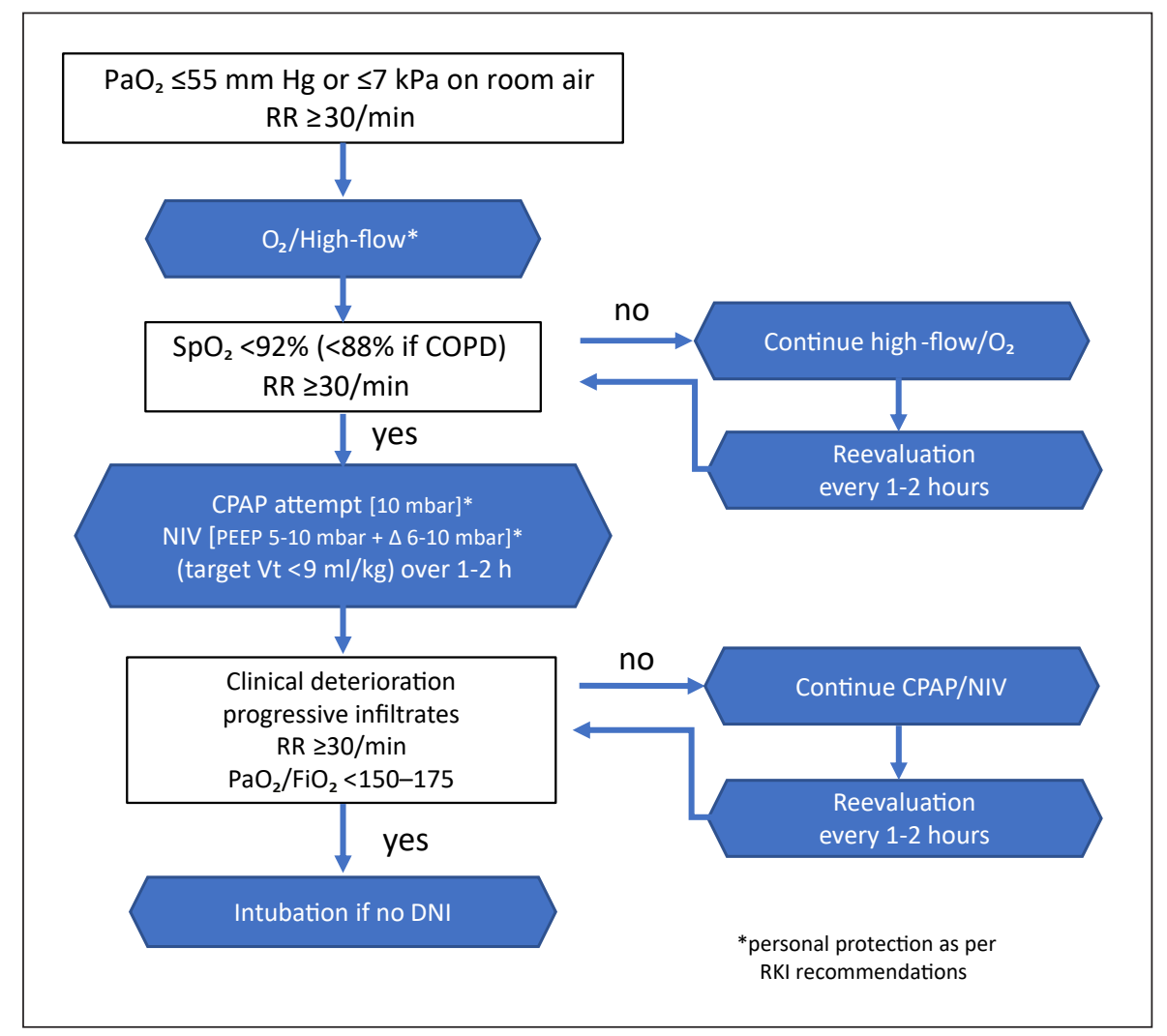

A similar recommendation of CPAP/NIV is provided in the NHS recommendations in the UK [114], but with the important advice that the intubation threshold should be low, and that, in the case of clinical deterioration (an increasing $\mathrm{O}_{2}$ requirement, steadily or rapidly falling $\mathrm{SaO}_{2}$, and/or an increase in respiratory rate and respiratory effort; see position statement 5), immediate intubation and MV should be considered. In their current review of the treatment of community-acquired severe respiratory viral infections, Arabi et al. [115] conclude in analogy to the previous evidence that NIV can be used in selected patients during early stages and in milder types of acute hypoxemic respiratory failure. At the same time, they point out, however, that in patients with no early improvement, NIV merely delays intubation rather than preventing it. A similar conclusion can be drawn from the currently available publications on ventilation in COVID-19.

The development from the onset of the first respiratory symptoms to ARDS and subsequent intubation, especially in COVID-19 patients, can proceed rapidly within a few days, making it necessary to make timely ventilation decisions $[20,113,116]$. The presence of bilateral pneumonia and a progressive worsening of the chest CT are unfavorable prognostic indicators of such a development $[44,117]$.

In principle, close monitoring is required to determine the criteria for NIV failure, with the option to rapidly transition to invasive ventilation $[5,49,110,113,118,119]$. Hence, treatment should ideally take place in an intensive care setting. Monitoring includes verifying oxygen saturation, blood gas levels, and tidal volumes, but also assessing the patient's clinical condition. Deteriorating oxygen supply with a $\mathrm{PaO}_{2} / \mathrm{FiO}_{2}<150$ or $175 \mathrm{~mm} \mathrm{Hg}$ after $1 \mathrm{~h}$ of NIV, a respiratory rate of $>30 / \mathrm{min}$, a high APACHE score, and a HACOR score $>5$ are associated with a significantly worse prognosis [120-123]. This results in the suggested therapy algorithm shown in Figure 2. However, the decision for or against implementing each of these steps should be based on the specific clinical situation, the $\mathrm{PaCO}_{2}$, the dynamics of respiratory insufficiency, and the clinician's experience.

\subsection{Practical Tips from a Hygiene Perspective}

Depending on the applied ventilation pressures or increasing flow values, both the use of NIV and intermittent NHF result in increased aerosol formation $[88,93,101$, 
124], which poses a potential risk of virus contamination in COVID-19 infections (see position statement 3). However, fear of infection with COVID-19 on the part of the medical staff must not be a primary reason for intubation. The protection of staff must, therefore, be a top priority. NIV failure should be identified early on so that intubation can be properly prepared and carried out. This prevents emergency intubation, which has been shown to be associated with poorer patient outcomes and, as a result of extended response times and inadequate protective measures, may put the emergency team at risk due to increased virus concentrations [2].

For the above reasons, leakage needs to be reduced to a minimum when using NIV. Oronasal masks, full-face masks, or respiratory helmets should, therefore, be used for COVID-19 cases. In addition, nonvented masks must be used. The ventilators used for COVID-19 patients should preferably be dual-hose systems. When using single-hose systems, a virus filter should be inserted between the interface and the intended leakage (whisper swivel) or the exhalation valve $[104,112]$.

When using a patient's own device and pressure setting adapted to the emergency situation, patients with previous CPAP or NIV require an appropriate mask and tube change, including the insertion of a virus filter [125].

\subsection{Summary}

In conclusion, currently available evidence $[49,13$, $118,126,127]$ essentially confirms the recommendations and guidelines $[4,5,99,101,126]$ for the treatment of ARF. According to these guidelines, moderately severe and severe ARDS associated with COVID-19 do not constitute a suitable indication for CPAP or NIV.

Key Statement 4.1. Oxygen therapy including NHF and NIV/CPAP using an oronasal mask or a respiratory helmet are therapy escalation options when regular oxygen therapy is insufficient and for as long as the criteria for endotracheal intubation are not met. Please refer to the current S3 guideline regarding the use of CPAP/NIV [5].

Key Statement 4.2. The pathophysiology of hypoxemic respiratory failure in COVID-19 is complex, and, according to current understanding, differs from other conditions accompanied by hypoxemia. Against this background, acute aggravation of hypoxemia, as well as a rapid increase in dyspnea and rapid clinical deterioration under CPAP/NIV, may occur. For this reason, continuous monitoring with readiness to carry out intubation must be ensured at all times.

Key Statement 4.3. The protection of staff with PPE should have top priority. Fear of contagion should not be a primary reason for intubation. For this reason, leakages should be reduced to a minimum. Closed systems (socalled nonvented masks) with an upstream virus deactivation filter in the expiratory system are safe and do not lead to increased aerosol formation.

By analogy, dual-hose systems with virus deactivation filters in the expiratory tube are also safe and do not lead to increased aerosol formation. Nonvented oronasal masks, full-face masks, or respiratory helmets should be used as interfaces. A virus deactivation filter should be inserted between the interface and the expiration device (intended leakage or expiration valve for single-hose systems).

\section{Position Statement 5: Continuity of Care in the Treatment of ARF}

\section{S. Kluge and P. Lepper compiled this statement.}

\subsection{Introduction}

Taking into account the findings described in the above position statements, this section intends to provide evidence-based treatment recommendations with due consideration of personalized medicine aspects. In contrast to disaster medicine, the personalized medicine approach means that individual patients can receive treatment as if there was unrestricted access to resources. This does not mean, however, that experimental therapies can or should be used indiscriminately just because all medical aspects of COVID-19 are not yet known. It also does not mean that therapies that are neither indicated nor pathophysiologically reasonable should be implemented.

The use of intensive medical care must be based on the principles of good clinical practice. Since no causal treatment is available to date, adjuvant therapy of COVID-19 patients needs to focus on maintaining or restoring homeostasis.

\subsection{Indication for Admission to the ICU}

Patients requiring more intensive care should be quickly identified in the hospital's emergency room. Acute sepsis- or comorbidity-associated organ dysfunction is to be assessed in this context. This assessment, similar to the evaluation of community-acquired pneumonia, is intended to identify the so-called minor criteria of the American Thoracic Society and of the Infectious Diseases Society of America (ATS/IDSA) and include potentially unstable comorbidities $[3,128]$. Patients requiring MV and/or vasopressor therapy (major criteria) should always be treated in the ICU. In patients with clinically manifest hypoperfu- 
sion, lactate should be measured initially. Regular reevaluation, adjusted to the initial severity of organ dysfunction, should be performed until clinical stability is achieved.

\section{Major Criteria}

1 Need for intubation and MV

2 Necessity to administer vasopressors (septic shock)

Various scores have been developed in recent years and evaluated in studies to predict patients who are at an increased risk of requiring intensive medical care or MV, and/ or catecholamine therapy, without the immediate need to initiate organ replacement therapy (i.e., without major criteria). All scores have in common that, clinical, laboratory chemical, and X-ray parameters of acute organ dysfunction are identified, which, when combined in different manners, produces approximately similar predictions. In meta-analyses, these scores were found to be consistently superior to the CRB-65 index in terms of risk prediction. The latter is therefore not applied to COVID-19.

\section{Minor Criteria}

A high risk of requiring intensive medical care exists if $>2$ of 9 minor criteria are met.

1 Severe acute respiratory failure $\left(\mathrm{PaO}_{2} \leq 55 \mathrm{~mm}\right.$ $\mathrm{Hg}$ or $\leq 7 \mathrm{kPa}$ on room air)

2 A respiratory rate of $\geq 30 / \mathrm{min}$

3 Multilobar infiltrates on chest X-ray

4 New disorder of consciousness

5 Systemic hypotension requiring aggressive volume therapy

6 Acute kidney failure (urea nitrogen $\geq 20 \mathrm{mg} / \mathrm{dL}$ )

7 Leukopenia (leukocytes $<4,000$ cells $/ \mathrm{mm}^{3}$ )

8 Thrombocytopenia (thrombocytes $<100,000$ cells $/ \mathrm{mm}^{3}$ )

9 Hypothermia (a body temperature $<36^{\circ} \mathrm{C}$ )

\subsection{Development of COVID-19 Patients in the Intensive Care Setting}

A significant proportion of patients with respiratory failure present with relevant hypoxemia, which often cannot be fully corrected, even with a high $\mathrm{FiO}_{2}$, including NHF. Lung compliance is relatively high in the majority of cases ( $\left.>50 \mathrm{~mL} / \mathrm{cm} \mathrm{H}_{2} \mathrm{O}\right)$ [34]. As a result of hypoxemia, these patients have a significantly increased respiratory drive and respiratory volumes of $>15 \mathrm{~L} / \mathrm{min}$. Determining the Horovitz index usually provides significantly lower values of around 120-150. The bilateral changes in Xray imaging or chest $\mathrm{CT}$ alone are often not sufficient to explain the severe oxygenation disorder of these patients.
When using a pulmonary arterial catheter, measurements show that some patients initially have normal pulmonary artery pressure and normal-to-reduced pulmonary vascular resistance in combination with a normal/ moderately increased cardiac output (range 6-9 L/min). The oxygenation disorder might, therefore, be explained by a relevant right/left shunt with impaired autoregulation of the pulmonary vasculature (impaired or absent "hypoxic pulmonary vasoconstriction") and severe distribution disorder (see recommendation 1). These patients should first be treated for hypoxemia, e.g., with NHF, nasal oxygen, or NIV, which can stabilize them.

\subsubsection{The Place of NIV}

With reference to the current S3 guideline of NIV for ARF [5], the following should be noted.

NIV can improve oxygenation in most patients with severe community-acquired pneumonia, but the failure rate is relatively high $[20,64]$. In addition to the severity of the clinical presentation, the extent of the oxygenation disorder can be a predictor of the success or failure of NIV. In general, a treatment attempt with NIV is justified in severe cases of COVID-19, especially in patients with COPD, with due consideration of the contraindications and termination criteria. In principle, close monitoring is required to identify the criteria of NIV failure, with the ability to rapidly transition to invasive ventilation [5]. Therefore, treatment should ideally take place in an ICU. Major arguments for choosing the ICU as the place to perform NIV as an alternative to invasive ventilation are: the ability to continuously monitor the patient and to initiate potentially indicated vital treatments without delay. Concerning the qualifications of medical and nursing staff, NIV places the same high demands on staff as invasive ventilation does. The structural prerequisites must, therefore, be met.

Exceptions are patients suffering from ventilatory failure, e.g., in the context of an acute exacerbation of COPD. In specific cases, ventilation can also be performed in an intermediate ICU specializing in ventilation. In patients with preexisting NIV, the transition between clinically stable chronic ventilatory failure and incipient decompensation is often blurred. Here, NIV can, in some cases, also be carried out in the general ward, provided that the technical and structural conditions are met.

\subsubsection{Evaluation of Clinical Development and Management in ICU}

The evaluation of patients should be oriented around physiological parameters (recapillarization time, lactate, diuresis, and normalization of respiratory rate) rather 
Table 2. Overview of respiratory support in severe acute respiratory insufficiency as available to date

\begin{tabular}{llllll}
\hline Study & $\begin{array}{l}\text { Critically ill } \\
\text { patients, } n\end{array}$ & HFNC, $n$ & NIV, $n$ & MV, $n$ & ECMO, $n$ \\
\hline China & & & & & \\
Zhou et al. [22], 2020 & 50 & $41(33[81 \%])$ & $26(24[92 \%])$ & $32(31[97 \%])$ & $3(3[100 \%])$ \\
Wu et al. [65], 2020 & 84 & n.r. & n.r. & $\begin{array}{l}67(44[66 \%]) \\
9 \text { still in hospital }\end{array}$ & n.r. \\
Wang et al. [127], 2020 & 344 & $35(28[80 \%])$ & $34(27[79 \%])$ & $100(97[97 \%])$ & n.r. \\
\hline UK & & & & $1,795(1,209[67 \%])$ & n.r. \\
\hline ICNARC [129], 2020 & 2,016 & together $821^{\mathrm{a}}(160[20 \%])$ & & \\
\hline
\end{tabular}

Values in parentheses show the number and percentage of deceased patients. ECMO, extracorporeal membrane oxygenation; HFNC, nasal high-flow cannula; MV, mechanical ventilation; NIV, noninvasive ventilation; n.r., not reported.

a The total of HFNC and NIV patients together.

than numerical target parameters to estimate a sufficient oxygen supply. If the patient has a central venous access or pulmonary catheter, it is helpful to determine the central or mixed venous oxygen saturation.

A deterioration in oxygen saturation with $\mathrm{PaO}_{2} / \mathrm{FiO}_{2}$ $<150$ or $175 \mathrm{~mm} \mathrm{Hg}$ after $1 \mathrm{~h}$ of NIV, a respiratory rate $>30 / \mathrm{min}$, a high APACHE score, and a HACOR score $>5$ are indications for endotracheal intubation in patients with a curative treatment goal [120-123].

In patients who are already intubated and ventilated, a prone position and a high PEEP are associated with varying success rates. These patients should be ventilated as recommended per S3 guideline recommendations [4]. Due to the favorable risk/benefit ratio, an attempt should be made to improve the condition of patients with such measures. High PEEP levels in these patients also carry the risk of acute cor pulmonale if pulmonary embolism can be ruled out. Recruitment maneuvers are often not promising when compliance is good. The need for sedation can be high in this phase of the disease. Volume management should be restrictive while taking into account that patients have a disproportionately high fluid loss due to a high respiratory minute volume and fever.

In the course of the disease, which can sometimes last for weeks, compliance often decreases, and the pulmonary situation becomes increasingly similar to COVID-19 pneumonia type $\mathrm{H}[4,34]$.

In COVID-19 patients with respiratory failure in whom invasive ventilation using the above-described measures is not sufficient to ensure adequate oxygen uptake and $\mathrm{CO}_{2}$ elimination, ECMO should be considered.
This is on condition that it is medically indicated and the patient has consented to its use. With regard to further management, please see the current S3 guideline on invasive ventilation and the use of extracorporeal procedures in ARF [4].

It is difficult to compare data on the outcome of the various types of respiratory support as no precise settings and parameters have been reported. Table 2 provides an overview of the evaluations from China and the UK. Whether these figures also reflect the situation in Germany cannot be assessed at this stage, as the specific figures are not yet available. An overview of respiratory support in acute respiratory insufficiency shows the heterogeneity of the condition in severe courses of the disease (Table 2).

Key Position Statement 5.1. In COVID-19 patients, NIV in hypoxemic ARF should be performed in an ICU or equivalent setting by adequately experienced staff.

Key Statement 5.2. Please consult the applicable S3 guideline [4] for the implementation of invasive ventilation.

Key Statement 5.3. In COVID-19 patients with respiratory failure in whom invasive ventilation using the above-described measures is not sufficient to ensure adequate oxygen uptake and $\mathrm{CO}_{2}$ elimination, ECMO should be considered. This is based on the condition that it is medically indicated and the patient's consent has been received.

Finding 5.1. COVID-19 patients with ARF present a heterogeneous picture, even during treatment in ICU, and cannot be indiscriminately classified into one of the categories according to the Berlin definition of ARDS. 


\section{Acknowledgments}

We want to thank Prof. Tom Schaberg and Prof. Inge HansenSchaberg for reviewing the manuscript for content and form.

\section{Disclosure Statement}

The authors declare that there are no conflicts of interest.

\section{Author Contributions}

All authors contributed equally to the paper. They contributed differently to the different position statements: position statement 1: S.E., M.P., and T.V.; position statement 2: W.J.R. and TB; position statement 3: J.G. and D.D.; position statement 4: M.W., W.W., and B.S.; and position statement 5: S.K. and P.M.L. The consensus process was led by T.B., who edited the full manuscript.

\section{References}

1 An der Heiden M, Buchholz U. [Internet] Modellierung von Beispielszenarien der SARS-CoV-2 Epidemie 2020 in Deutschland [cited 2020]. Available from: https://doi. org/10.25646/ 6571.2.

2 Kluge S, Janssens U, Welte T, Weber-Carstens S, Marx G, Karagiannidis C. Recommendations for critically ill patients with COVID-19. Med Klin Intensivmed Notf Med. 2020; 115(3):175-7. German.

3 Ewig S, Höffken G, Kern WV, Rohde G, Flick $\mathrm{H}$, Krause R, et al. Management of adult community-acquired pneumonia and prevention - update 2016. Pneumologie. $2016 \mathrm{Mar}$; 70(3):151-200. German.

4 Fichtner F, Moerer O, Laudi S, WeberCarstens S, Nothacker M, Kaisers U; Investigators and the Guideline Group on Mechanical Ventilation and Extracorporeal Membrane Oxygena tion in Acute Respiratory Insufficiency. Mechanical Ventilation and Extracorporeal Membrane Oxygena tion in Acute Respiratory Insufficiency. Dtsch Arztebl Int. 2018 Dec;115(50):840-7.

5 Westhoff M, Schönhofer B, Neumann P, Bickenbach J, Barchfeld T, Becker H, et al. Non-invasive mechanical ventilation in acute respiratory failure. Pneumologie. 2015 Dec; 69(12):719-56. German.

6 Huang C, Wang Y, Li X, Ren L, Zhao J, Hu Y, et al. Clinical features of patients infected with 2019 novel coronavirus in Wuhan, China. Lancet. 2020 Feb;395(10223):497-506.

7 Zhu N, Zhang D, Wang W, Li X, Yang B, Song J, et al.; China Novel Coronavirus Investigating and Research Team. A Novel Coronavirus from Patients with Pneumonia in China, 2019. N Engl J Med. 2020 Feb;382(8):727-33.

8 Chen N, Zhou M, Dong X, Qu J, Gong F, Han $\mathrm{Y}$, et al. Epidemiological and clinical characteristics of 99 cases of 2019 novel coronavirus pneumonia in Wuhan, China: a descriptive study. Lancet. 2020 Feb;395(10223):507-13.

9 Wu Z, McGoogan JM. Characteristics of and Important Lessons from the Coronavirus Disease 2019 (COVID-19) Outbreak in China: Summary of a Report of 72314 Cases from the Chinese Center for Disease Control and Prevention. JAMA. 2020 Feb;323(13):1239.

10 South AM, Diz DI, Chappell MC. COVID-19, ACE2, and the cardiovascular consequences.
Am J Physiol Heart Circ Physiol. 2020 May; 318(5):H1084-90.

11 Zheng YY, Ma YT, Zhang JY, Xie X. COVID-19 and the cardiovascular system. Nat Rev Cardiol. 2020 May;17(5):259-60.

12 Cheung KS, Hung IF, Chan PP, Lung KC, Tso E, Liu R, et al. Gastrointestinal Manifestations of SARS-CoV-2 Infection and Virus Load in Fecal Samples from the Hong Kong Cohort and Systematic Review and Meta-analysis. Gastroenterology. 2020. DOI: 10.1053/j.gastro.2020.03.06

13 Lin L, Jiang X, Zhang Z, Huang S, Zhang Z, Fang Z, et al. Gastrointestinal symptoms of 95 cases with SARS-CoV-2 infection. Gut. 2020 Jun;69(6):997-1001.

14 Channappanavar R, Perlman S. Pathogenic human coronavirus infections: causes and consequences of cytokine storm and immunopathology. Semin Immunopathol. $2017 \mathrm{Jul}$; 39(5):529-39.

15 Siddiqi HK, Mehra MR. COVID-19 illness in native and immunosuppressed states: A clinical-therapeutic staging proposal. J Heart Lung Transplant. 2020 May;39(5):405-7.

16 Peiris JS, Chu CM, Cheng VC, Chan KS, Hung IF, Poon LL, et al.; HKU/UCH SARS Study Group. Clinical progression and viral load in a community outbreak of coronavirus-associated SARS pneumonia: a prospective study. Lancet. 2003 May;361(9371): 1767-72.

17 Yang X, Yu Y, Xu J, Shu H, Xia J, Liu H, et al. Clinical course and outcomes of critically ill patients with SARS-CoV-2 pneumonia in Wuhan, China: a single-centered, retrospective, observational study. Lancet Respir Med. 2020 May;8(5):475-81.

18 Tetro JA. Is COVID-19 receiving ADE from other coronaviruses? Microbes Infect. 2020 Mar;22(2):72-3.

19 Tilocca B, Soggiu A, Musella V, Britti D, Sanguinetti M, Urbani A, et al. Molecular basis of COVID-19 relationships in different species: a one health perspective. Microbes Infect. 2020. DOI: 10.1016/j.micinf.2020.03.002.

20 Wang D, Hu B, Hu C, Zhu F, Liu X, Zhang J, et al. Clinical Characteristics of 138 Hospitalized Patients With 2019 Novel CoronavirusInfected Pneumonia in Wuhan, China. JAMA. 2020 Feb;323(11):1061.
21 Ruan Q, Yang K, Wang W, Jiang L, Song J. Clinical predictors of mortality due to COVID-19 based on an analysis of data of $150 \mathrm{pa}-$ tients from Wuhan, China. Intensive Care Med. 2020 May;46(5):846-8.

22 Zhou F, Yu T, Du R, Fan G, Liu Y, Liu Z, et al. Clinical course and risk factors for mortality of adult inpatients with COVID-19 in Wuhan, China: a retrospective cohort study. Lancet. 2020 Mar;395(10229):105462.

23 Gu J, Gong E, Zhang B, Zheng J, Gao Z, Zhong $Y$, et al. Multiple organ infection and the pathogenesis of SARS. J Exp Med. 2005 Aug; 202(3):415-24.

24 Ai T, Yang Z, Hou H, Zhan C, Chen C, Lv W, et al. Correlation of Chest CT and RT-PCR Testing in Coronavirus Disease 2019 (COVID-19) in China: A Report of 1014 Cases. Radiology. 2020 Feb;200642:200642.

25 Fang Y, Zhang H, Xu Y, Xie J, Pang P, Ji W. CT Manifestations of Two Cases of 2019 Novel Coronavirus (2019-nCoV) Pneumonia. Radiology. 2020 Apr;295(1):208-9.

26 Duan YN, Qin J. Pre- and Posttreatment Chest CT Findings: 2019 Novel Coronavirus (2019-nCoV) Pneumonia. Radiology. 2020 Apr;295(1):21.

27 Bai HX, Hsieh B, Xiong Z, Halsey K, Choi JW, Tran TM, et al. Performance of radiologists in differentiating COVID-19 from viral pneumonia on chest CT. Radiology. 2020 Mar; 200823:200823

28 Maiolo G, Collino F, Vasques F, Rapetti F, Tonetti T, Romitti F, et al. Reclassifying Acute Respiratory Distress Syndrome. Am J Respir Crit Care Med. 2018 Jun;197(12):1586-95.

29 Gattinoni L, Chiumello D, Caironi P, Busana M, Romitti F, Brazzi L, et al. COVID-19 pneumonia: different respiratory treatments for different phenotypes? Intensive Care Med. 2020. DOI: $10.1007 / \mathrm{s} 00134-020-06033-2$.

30 Dreher M, Kersten A, Bickenbach J et al. The Characteristics of 50 Hospitalised COVID-19 Patients with and without ARDS. Dtsch Arztebl Int. 2020 Apr;117:271-8.

31 Han R, Huang L, Jiang H, Dong J, Peng H, Zhang D. Early Clinical and CT Manifestations of Coronavirus Disease 2019 (COVID-19) Pneumonia. AJR Am J Roentgenol. 2020. DOI: 10.2214/AJR.20.22961. 
32 Zhao W, Zhong Z, Xie X, Yu Q, Liu J. Relation between Chest CT Findings and Clinical Conditions of Coronavirus Disease (COVID-19) Pneumonia: A Multicenter Study. AJR Am J Roentgenol. 2020 May;214(5):1072-7.

33 Li Y, Xia L. Coronavirus Disease 2019 (COVID-19): Role of Chest CT in Diagnosis and Management. AJR Am J Roentgenol. 2020 Jun;214(6):1280-6.

34 Gattinoni L, Coppola S, Cressoni M, Busana M, Rossi S, Chiumello D. COVID-19 Does Not Lead to a "Typical" Acute Respiratory Distress Syndrome. Am J Respir Crit Care Med. 2020 May;201(10):1299-300.

35 Barach A, Martin J, Eckman M, et al. Positive Pressure Respiration and Its Application to the Treatment of Acute Pulmonary Edema. Ann Intern Med. 1938;12(6):754-9.

36 Barach AL, Eckman M, et al. Studies on positive pressure respiration; general aspects and types of pressure breathing; effects on respiration and circulation at sea level. J Aviat Med. 1946 Aug;17:290-32.

37 Mascheroni D, Kolobow T, Fumagalli R, Moretti MP, Chen V, Buckhold D. Acute respiratory failure following pharmacologically induced hyperventilation: an experimental animal study. Intensive Care Med. 1988; 15(1):8-14.

38 Brochard L, Slutsky A, Pesenti A. Mechanical Ventilation to Minimize Progression of Lung Injury in Acute Respiratory Failure. Am J Respir Crit Care Med. 2017 Feb;195(4):43842.

39 Xu Z, Shi L, Wang Y, Zhang J, Huang L, Zhang $\mathrm{C}$, et al. Pathological findings of COVID-19 associated with acute respiratory distress syndrome. Lancet Respir Med. 2020 Apr; $8(4): 420-2$.

40 Ding Y, Wang H, Shen H, Li Z, Geng J, Han $\mathrm{H}$, et al. The clinical pathology of severe acute respiratory syndrome (SARS): a report from China. J Pathol. 2003 Jul;200(3):282-9.

$41 \mathrm{Ng}$ DL, Al Hosani F, Keating MK, Gerber SI, Jones TL, Metcalfe MG, et al. Clinicopathologic, Immunohistochemical, and Ultrastructural Findings of a Fatal Case of Middle East Respiratory Syndrome Coronavirus Infection in the United Arab Emirates, April 2014. Am J Pathol. 2016 Mar;186(3):652-8.

42 Grasselli G, Pesenti A, Cecconi M. Critical Care Utilization for the CO-VID-19 Outbreak in Lombardy, Italy: Early Experience and Forecast during an Emergency Response. JAMA. 2020;323(16):1545.

43 Zhou F, Yu T, Du R, Fan G, Liu Y, Liu Z, et al. Clinical course and risk factors for mortality of adult inpatients with COVID-19 in Wuhan, China: a retrospective cohort study. Lancet. 2020 Mar;395(10229):1054-62.

44 Shi H, Han X, Jiang N, Cao Y, Alwalid O, Gu $\mathrm{J}$, et al. Radiological findings from 81 patients with COVID-19 pneumonia in Wuhan, China: a descriptive study. Lancet Infect Dis. 2020 Apr;20(4):425-34.

45 Guo T, Fan Y, Chen M, Wu X, Zhang L, He T, et al. Cardiovascular Implications of Fatal
Outcomes of Patients with Coronavirus Disease 2019 (COVID-19). JAMA Cardiol. 2020. DOI: 10.1001/jamacardio.2020.1017.

46 Gao C, Wang Y, Gu X, Shen X, Zhou D, Zhou $S$, et al.; Community-Acquired PneumoniaChina Network. Association between Cardiac Injury and Mortality in Hospitalized Patients Infected with Avian Influenza A (H7N9) Virus. Crit Care Med. 2020 Apr;48(4):451-8.

47 Cui S, Chen S, Li X, Liu S, Wang F. Prevalence of venous thromboembolism in patients with severe novel coronavirus pneumonia. J Thromb Haemost. 2020 Jun;18(6):1421-4.

48 Schaberg T, Bauer T, Dalhoff K, Ewig S, Köhler D, Lorenz J, et al. Management of a New Influenza A/H1N1 Virus Pandemic within the Hospital. Statement of the German Society of Pneumology. Pneumologie. 2010 Feb;64(2):124-9. German.

49 Grasselli G, Zangrillo A, Zanella A, Antonelli M, Cabrini L, Castelli A, et al.; COVID-19 Lombardy ICU Network. Baseline Characteristics and Outcomes of 1591 Patients Infected With SARS-CoV-2 Admitted to ICUs of the Lombardy Region, Italy. JAMA. 2020 Apr; 323(16): 1574 .

50 Onder G, Rezza G, Brusaferro S. Case-Fatality Rate and Characteristics of Patients Dying in Relation to COVID-19 in Italy. JAMA. 2020. DOI: 10.1001/jama.2020.4683.

51 Wang W, Xu Y, Gao R, Lu R, Han K, Wu G, et al. Detection of SARS-CoV-2 in Different Types of Clinical Specimens. JAMA. 2020. DOI: 10.1001/jama.2020.3786.

52 Pan Y, Zhang D, Yang P, Poon LL, Wang Q. Viral load of SARS-CoV-2 in clinical samples. Lancet Infect Dis. 2020 Apr;20(4):411-2.

53 Zou L, Ruan F, Huang M, Liang L, Huang H, Hong Z, et al. SARS-CoV-2 Viral Load in Upper Respiratory Specimens of Infected $\mathrm{Pa}$ tients. N Engl J Med. 2020 Mar;382(12): 1177-9.

54 Fang Y, Zhang H, Xie J, Lin M, Ying L, Pang $\mathrm{P}$, et al. Sensitivity of Chest CT for COVID-19: comparison to RT-PCR. Radiology. 2020. DOI: 10.1148/radiol.2020200432.

55 Jiang J, Yang J, Jin Y et al. Role of qSOFA in predicting mortality of pneumonia: a systematic review and meta-analysis. Medicine. 2018;97: e12634.

56 Shi S, Qin M, Shen B, Cai Y, Liu T, Yang F, et al. Association of Cardiac Injury with Mortality in Hospitalized Patients with COVID-19 in Wuhan, China. JAMA Cardiol. 2020. DOI: 10.1001/jamacardio.2020.0950.

57 Madjid M, Safavi-Naeini P, Solomon SD, Vardeny O. Potential Effects of Coronaviruses on the Cardiovascular System: A Review. JAMA Cardiol. 2020. DOI:10.1001/jamacardio.2020.1286.

58 Seymour CW, Liu VX, Iwashyna TJ, Brunkhorst FM, Rea TD, Scherag A, et al. Assessment of Clinical Criteria for Sepsis: For the Third International Consensus Definitions for Sepsis and Septic Shock (Sepsis-3). JAMA. 2016 Feb;315(8):762-74

59 Tang N, Li D, Wang X, Sun Z. Abnormal co- agulation parameters are associated with poor prognosis in patients with novel coronavirus pneumonia. J Thromb Haemost. 2020 Apr; 18(4):844-7.

60 Yin S, Huang M, Li D, Tang N. Difference of coagulation features between severe pneumonia induced by SARS-CoV2 and non-SARSCoV2. J Thromb Thrombolysis. 2020. DOI: 10.1007/s11239-020-02105-8.

61 Dembinski R, Mielck F. ARDS - An Update Part 1: Epidemiology, Pathophysiology and Diagnosis. Anasthesiol Intensivmed Notfallmed Schmerzther. 2018 Feb;53(2):102-11. German.

62 Ranieri VM, Rubenfeld GD, Thompson BT, Ferguson ND, Caldwell E, Fan E, et al.; ARDS Definition Task Force. Acute respiratory distress syndrome: the Berlin definition. JAMA. 2012 Jun;307(23):2526-33.

63 Arentz M, Yim E, Klaff L, Lokhandwala S, Riedo FX, Chong M, et al. Characteristics and Outcomes of 21 Critically Ill Patients With COVID-19 in Washington State. JAMA. 2020 Mar;323(16):1612.

64 Yang X, Yu Y, Xu J, Shu H, Xia J, Liu H, et al. Clinical course and outcomes of critically ill patients with SARS-CoV-2 pneumonia in Wuhan, China: a single-centered, retrospective, observational study. Lancet Respir Med. 2020 May;8(5):475-81.

65 Wu C, Chen X, Cai Y, Xia J, Zhou X, Xu S, et al. Risk Factors Associated with Acute Respiratory Distress Syndrome and Death in Patients with Coronavirus Disease 2019 Pneumonia in Wuhan, China. JAMA Intern Med. 2020. DOI: 10.1001/jamainternmed.2020.0994.

66 Bialek S, Boundy E, Bowen V, Chow N, Cohn A, Dowling N, et al.; CDC COVID-19 Response Team. Severe Outcomes Among Patients with Coronavirus Disease 2019 (COVID-19) - United States, February 12-March 16, 2020. MMWR Morb Mortal Wkly Rep. 2020 Mar;69(12):343-6.

67 Zhu N, Zhang D, Wang W, Li X, Yang B, Song J, et al.; China Novel Coronavirus Investigating and Research Team. A Novel Coronavirus from Patients with Pneumonia in China, 2019. N Engl J Med. 2020 Feb;382(8):727-33.

68 Papineni RS, Rosenthal FS. The size distribution of droplets in the exhaled breath of healthy human subjects. J Aerosol Med. 1997; 10(2):105-16.

69 Brown JR, Tang JW, Pankhurst L, Klein N, Gant V, Lai KM, et al. Influenza virus survival in aerosols and estimates of viable virus loss resulting from aerosolization and air-sampling. J Hosp Infect. 2015 Nov;91(3):278-81.

70 Yan J, Grantham M, Pantelic J, Bueno de Mesquita PJ, Albert B, Liu F, et al.; EMIT Consortium. Infectious virus in exhaled breath of symptomatic seasonal influenza cases from a college community. Proc Natl Acad Sci USA. 2018 Jan;115(5):1081-6.

71 Leung NH, Chu DK, Shiu EY, Chan KH, McDevitt JJ, Hau BJ, et al. Respiratory virus shedding in exhaled breath and efficacy of face masks. Nat Med. 2020 May;26(5):67680. 
72 Fabian P, McDevitt JJ, DeHaan WH, Fung $\mathrm{RO}$, Cowling BJ, Chan KH, et al. Influenza virus in human exhaled breath: an observational study. PLoS One. 2008 Jul;3(7):e2691.

73 Tang JW, Nicolle AD, Klettner CA, Pantelic J, Wang L, Suhaimi AB, et al. Airflow dynamics of human jets: sneezing and breathing - potential sources of infectious aerosols. PLoS One. 2013;8(4):e59970.

74 Bischoff WE, Swett K, Leng I, Peters TR. Exposure to influenza virus aerosols during routine patient care. J Infect Dis. 2013 Apr; 207(7):1037-46.

75 Köhler D, Fleischer W, editors. Inhalationstherapie. Munich: Arcis Verlag; 2000.

76 Wang B, Zhang A, Sun JL, Liu H, Hu J, Xu LX. Study of SARS transmission via liquid droplets in air. J Biomech Eng. 2005 Feb;127(1): 32-8.

77 Blachere FM, Lindsley WG, Pearce TA, Anderson SE, Fisher M, Khakoo R, et al. Measurement of airborne influenza virus in a hospital emergency department. Clin Infect Dis. 2009 Feb;48(4):438-40

78 Yang W, Elankumaran S, Marr LC. Concentrations and size distributions of airborne influenza A viruses measured indoors at a health centre, a day-care centre and on aeroplanes. J R Soc Interface. 2011 Aug;8(61) 1176-84.

79 Alford RH, Kasel JA, Gerone PJ, Knight V. Human influenza resulting from aerosol inhalation. Proc Soc Exp Biol Med. 1966 Jul; 122(3):800-4.

80 van Doremalen N, Bushmaker T, Morris DH, Holbrook MG, Gamble A, Williamson BN, et al. Aerosol and Surface Stability of SARSCoV-2 as Compared with SARS-CoV-1. N Engl J Med. 2020 Apr;382(16):1564-7.

81 Cowling BJ, Ip DK, Fang VJ, Suntarattiwong $\mathrm{P}$, Olsen SJ, Levy J, et al. Aerosol transmission is an important mode of influenza A virus spread. Nat Commun. 2013;4(1):1935.

82 Simonds AK, Hanak A, Chatwin M, Morrell $\mathrm{M}$, Hall A, Parker $\mathrm{KH}$, et al. Evaluation of droplet dispersion during non-invasive ventilation, oxygen therapy, nebuliser treatment and chest physiotherapy in clinical practice: implications for management of pandemic influenza and other airborne infections. Health Technol Assess. 2010 Oct;14(46):13172

83 Köhler D, Simonides R, Rothfuss J, Vatsag E, Daikeler G, Matthys H. Aerosol Distribution Pattern of 16 Commonly Used Inhalation Instruments. Prax Klin Pneumol. 1983 Oct;37 Suppl 1:922-4.

84 Wan GH, Wu CL, Chen YF, Huang SH, Wang YL, Chen CW. Particle size concentration distribution and influences on exhaled breath particles in mechanically ventilated patients. PLoS One. 2014 Jan;9(1):e87088.

85 Munsiff SS, Li J, Cook SV, Piatek A, Laraque F, Ebrahimzadeh A, et al. Trends in drug-resistant Mycobacterium tuberculosis in New York City, 1991-2003. Clin Infect Dis. 2006 Jun;42(12):1702-10.
86 Hui DS, Chow BK, Ng SS, Chu LC, Hall SD, Gin T, et al. Exhaled air dispersion distances during noninvasive ventilation via different Respironics face masks. Chest. 2009 Oct 136(4):998-1005

87 Hui DS, Hall SD, Chan MT, Chow BK, Tsou JY, Joynt GM, et al. Noninvasive positivepressure ventilation: an experimental model to assess air and particle dispersion. Chest. 2006 Sep;130(3):730-40.

88 Fowler RA, Guest CB, Lapinsky SE, Sibbald WJ, Louie M, Tang P, et al. Transmission of severe acute respiratory syndrome during intubation and mechanical ventilation. Am J Respir Crit Care Med. 2004 Jun;169(11): 1198-202.

89 Raboud J, Shigayeva A, McGeer A, Bontovics E, Chapman M, Gravel D, et al. Risk factors for SARS transmission from patients requiring intubation: a multicentre investigation in Toronto, Canada. PLoS One. 2010 May; 5(5):e10717.

90 Thompson KA, Pappachan JV, Bennett AM, Mittal H, Macken S, Dove BK, et al.; EASE Study Consortium. Influenza aerosols in UK hospitals during the H1N1 (2009) pandemic-the risk of aerosol generation during medical procedures. PLoS One. 2013; 8(2):e56278.

91 Canelli R, Connor CW, Gonzalez M, Nozari A, Ortega R. Barrier Enclosure during Endotracheal Intubation. N Engl J Med. 2020 May; 382(20):1957-8.

92 Bräunlich J, Goldner F, Wirtz H. Nasal highflow eliminates $\mathrm{CO} 2$ from lower airways. Respir Physiol Neurobiol. 2017 Aug;242:86-

93 Hui DS, Chow BK, Lo T, Tsang OT, Ko FW, $\mathrm{Ng}$ SS, et al. Exhaled air dispersion during high-flow nasal cannula therapy versus CPAP via different masks. Eur Respir J. 2019 Apr; 53(4): 1802339

94 Kotoda M, Hishiyama S, Mitsui K, et al. Assessment of the potential for pathogen dispersal during high-flow nasal therapy. J Hosp Infect. 2019. DOI: 10.1016/j. jhin.2019.11.010

95 Leung CC, Joynt GM, Gomersall CD, Wong WT, Lee A, Ling L, et al. Comparison of highflow nasal cannula versus oxygen face mask for environmental bacterial contamination in critically ill pneumonia patients: a randomized controlled crossover trial. J Hosp Infect. 2019 Jan;101(1):84-7.

96 He G, Han Y, Fang Q et al. Clinical experience of high-flow nasal cannula oxygen therapy in severe corona virus disease 2019 (COVID-19) patients. Zhejiang Da Xue Xue Bao Yi Xue Ban. 2020;49:0.

97 Loeb M, McGeer A, Henry B, Ofner M, Rose D, Hlywka T, et al. SARS among critical care nurses, Toronto. Emerg Infect Dis. 2004 Feb; 10(2):251-5

98 Edwards DA, Man JC, Brand P, Katstra JP, Sommerer K, Stone HA, et al. Inhaling to mitigate exhaled bioaerosols. Proc Natl Acad Sci USA. 2004 Dec;101(50):17383-8.
99 Rochwerg B, Brochard L, Elliott MW, Hess D, Hill NS, Nava S, et al. Official ERS/ATS clinical practice guidelines: noninvasive ventilation for acute respiratory failure. Eur Respir J. 2017 Aug;50(2):1602426.

100 World Health Organization. IMAI district clinician manual: hospital care for adolescents and adults: guidelines for the management of illnesses with limited resources. 2011.

101 World Health Organization. [Internet] Clinical management of severe acute respiratory infection (SARI) when COVID-19 disease is suspected: interim guidance [cited 13 March 2020]. Available from: https://apps.who.int/iris/handle/ 10665/331446

102 Pediatric Acute Lung Injury Consensus Conference Group. Pediatric acute respiratory distress syndrome: consensus recommendations from the Pediatric Acute Lung Injury Consensus Conference. Pediatr Crit Care Med. 2015 Jun;16(5):42839.

103 Riviello ED, Kiviri W, Twagirumugabe T, Mueller A, Banner-Goodspeed VM, Officer $L$, et al. Hospital Incidence and Outcomes of the Acute Respiratory Distress Syndrome Using the Kigali Modification of the Berlin Definition. Am J Respir Crit Care Med. 2016 Jan;193(1):52-9.

104 Robert Koch-Institut. [Internet] Arbeitskreis STAKOB 2020. Available from: https://www.rki.de/DE/Content/Kommissionen/Stakob/Behandlungszentren/Behandlungszentren_node.html

105 Nehls W, Delis S, Haberland B, et al. Management of Patients with COVID-19 - Recommendations from a Palliative Care Perspective. Pneumologie. 2020. DOI: 10.1055/ a-1156-2759. German.

106 Rhodes A, Evans LE, Alhazzani W, Levy MM, Antonelli M, Ferrer R, et al. Surviving Sepsis Campaign: International Guidelines for Management of Sepsis and Septic Shock: 2016. Crit Care Med. 2017 Mar;45(3):486552.

107 Pan C, Chen L, Lu C, Zhang W, Xia JA, Sklar $\mathrm{MC}$, et al. Lung Recruitability in COVID19-associated Acute Respiratory Distress Syndrome: A Single-Center Observational Study. Am J Respir Crit Care Med. 2020 May;201(10):1294-7.

108 Bellani G, Laffey JG, Pham T, Madotto F, Fan E, Brochard L, et al.; LUNG SAFE Investigators; ESICM Trials Group. Noninvasive Ventilation of Patients with Acute Respiratory Distress Syndrome. Insights from the LUNG SAFE Study. Am J Respir Crit Care Med. 2017 Jan;195(1):67-77.

109 Frat JP, Ragot S, Coudroy R, Constantin JM, Girault C, Prat G, et al.; REVA network. Predictors of Intubation in Patients with Acute Hypoxemic Respiratory Failure Treated with a Noninvasive Oxygenation Strategy. Crit Care Med. 2018 Feb;46(2): 208-15. 
110 Frat JP, Thille AW, Mercat A, Girault C, Ragot S, Perbet S, et al.; FLORALI Study Group; REVA Network. High-flow oxygen through nasal cannula in acute hypoxemic respiratory failure. N Engl J Med. 2015 Jun; 372(23):2185-96.

111 Carteaux G, Millán-Guilarte T, De Prost N, Razazi K, Abid S, Thille AW, et al. Failure of Noninvasive Ventilation for De Novo Acute Hypoxemic Respiratory Failure: Role of Tidal Volume. Crit Care Med. 2016 Feb;44(2): 282-90.

112 Karagiannidis C, Bein T, Windisch W. Was hat sich seit Publikation der S3-Leitlinie „Invasive Beatmung und Einsatz extrakorporaler Verfahren" getan? Pneumologie. 2020 Jan;74(1):46-9.

113 Harari SA, Vitacca M, Blasi F et al. [Internet] Managing the respiratory care of patients with COVID-19. Italian Thoracic Society Associazione Italiana Pneumologi Ospedalieri - Societa Italiana Di Pneumologia; 2020. Available from: http://www.aiponet.it2020.

114 NHS. [Internet] Guidance for the role and use of non-invasive respiratory support in adult patients with COVID-19 (confirmed or suspected), March 26, 2020 [cited April 1 2020]. Available from: https://www.england.nhs.uk/coronavirus/wp-content/uploads/sites/52/2020/03/CLEARED_Specialty-guide_-NIV-respiratory-support-andcoronavirus-v2-26-March-003.pdf

115 Arabi YM, Fowler R, Hayden FG. Critical care management of adults with community-acquired severe respiratory viral infection. Intensive Care Med. 2020 Feb;46(2): 315-28.
116 Goh KJ, Choong MC, Cheong EH, Kalimuddin S, Duu Wen S, Phua GC, et al. Rapid Progression to Acute Respiratory Distress Syndrome: Review of Current Understanding of Critical Illness from COVID-19 Infection. Ann Acad Med Singapore. 2020 Mar;49(3): 108-18.

117 Du Y, Tu L, Zhu P, Mu M, Wang R, Yang P, et al. Clinical Features of 85 Fatal Cases of COVID-19 from Wuhan. A Retrospective Observational Study. Am J Respir Crit Care Med. 2020 Jun;201(11):1372-9.

118 [118] Liang T. Handbook of COVID-19 Prevention and Treatment.

119 Phua J, Weng L, Ling L, Egi M, Lim CM, Divatia JV, et al.; Asian Critical Care Clinical Trials Group. Intensive care management of coronavirus disease 2019 (COVID-19): challenges and recommendations. Lancet Respir Med. 2020 May;8(5):506-17.

120 Wallet F, Schoeffler M, Reynaud M, Duperret S, Workineh S, Viale JP. Factors associated with noninvasive ventilation failure in postoperative acute respiratory insufficiency: an observational study. Eur J Anaesthesiol. 2010 Mar;27(3):270-4.

121 Antonelli M, Conti G, Moro ML, Esquinas A, Gonzalez-Diaz G, Confalonieri M, et al. Predictors of failure of noninvasive positive pressure ventilation in patients with acute hypoxemic respiratory failure: a multi-center study. Intensive Care Med. 2001 Nov; 27(11):1718-28

122 Bourke SC, Piraino T, Pisani L, Brochard L, Elliott MW. Beyond the guidelines for noninvasive ventilation in acute respiratory failure: implications for practice. Lancet Respir Med. 2018 Dec;6(12):935-47.

123 Duan J, Han X, Bai L, Zhou L, Huang S. Assessment of heart rate, acidosis, consciousness, oxygenation, and respiratory rate to predict noninvasive ventilation failure in hypoxemic patients. Intensive Care Med. 2017 Feb;43(2):192-9.
124 Guan L, Zhou L, Zhang J, Peng W, Chen R More awareness is needed for severe acute respiratory syndrome coronavirus 2019 transmission through exhaled air during non-invasive respiratory support: experience from China. Eur Respir J. 2020 Mar; 55(3):2000352.

125 Baker JG, Sovani M. Case for continuing community NIV and CPAP during the COVID-19 epidemic. Thorax. 2020 May;75(5): 368.

126 Alhazzani W, Møller MH, Arabi YM, Loeb M, Gong MN, Fan E, et al. Surviving Sepsis Campaign: Guidelines on the Management of Critically Ill Adults with Coronavirus Disease 2019 (COVID-19). Crit Care Med. 2020 Jun;48(6):e440-69.

127 Wang Y, Lu X, Li Y, Chen H, Chen T, Su N, et al. Clinical Course and Outcomes of 344 Intensive Care Patients with COVID-19. Am J Respir Crit Care Med. 2020 Jun; 201(11):1430-4.

128 Mandell LA, Wunderink RG, Anzueto A, Bartlett JG, Campbell GD, Dean NC, et al.; Infectious Diseases Society of America; American Thoracic Society. Infectious Diseases Society of America/American Thoracic Society consensus guidelines on the management of community-acquired pneumonia in adults. Clin Infect Dis. 2007 Mar; 44 Suppl 2:S27-72.

129 Intensive Care National Audit and Research Centre. [Internet] ICNARC report on COVID-19 in critical care [cited 17 April 2020] Available from: https://www.icnarc.org/ Our-Audit/Audits/Cmp/Reports 